\title{
Lapurdum
}

LAPURDUM Euskal ikerketen aldizkaria | Revue d'études basques |

Revista de estudios vascos | Basque studies review

$7 \mid 2002$

Numéro VII

\section{Bernardo Atxaga : un escritor cautivador}

\section{Gorka Aulestia}

\section{OpenEdition}

\section{Journals}

Edición electrónica

URL: http://journals.openedition.org/lapurdum/977

DOI: 10.4000/lapurdum.977

ISSN: 1965-0655

Editor

IKER

Edición impresa

Fecha de publicación: 1 octubre 2002

Paginación: 93-135

ISBN: 2-86781-321-2

ISSN: $1273-3830$

\section{Referencia electrónica}

Gorka Aulestia, « Bernardo Atxaga : un escritor cautivador », Lapurdum [En línea], 7| 2002, Publicado el 01 junio 2009, consultado el 19 abril 2019. URL : http://journals.openedition.org/lapurdum/977 ; DOI : 10.4000/lapurdum.977 


\section{Bernardo Atxaga : un escritor cautivador}

Gorka AULESTIA

Universidad de Deusto

Al abordar el tema dedicado a la poesía de Gabriel Aresti (Sancho el Sabio, 1998 : 22-30) resaltábamos su talante innovador y rupturista junto a la capacidad para iniciar a los jóvenes valores en el campo de la narrativa y sostenerlos en el de la poesía vasca : B. Atxaga (1951-), J. Azurmendi (1941-) R. Saizarbitoria (1944-), A. Urretabizkaia (1947-), A. Lertxundi (1.945-), J.M. Irigoien (1948-), K. Izagirre (1953-), J. Sarrionandia (1958-), I. Sarasola (1946-), L. Haranburu - Altuna (1947), L.M. Mujika (1939-), X. Kintana (1946-), P. Urkizu (1946- ), J.M. Iturralde (1951-), etc. Si la época de los escritores rupturistas (J. Mirande, G. Aresti y "Txillardegi") supuso un cambio notable con respecto a los temas y al talante de los escritores de la Preguerra Civil, podemos afirmar otro tanto en cuanto al estilo de los jóvenes escritores de la década de los 70 con respecto a los rupturistas, a pesar de que varios de ellos, como B. Atxaga, fueron muy cercanos a la persona de G. Aresti. El realismo social propugnado por el poeta bilbaíno (fruto, en gran medida de la influencia de sus amigos B. de Otero y G. Celaya) y el estilo de su libro Harri eta Herri (1964), fueron preteridos por muchos de los mencionados escritores más jóvenes. La retórica de la poesía social dejó paso a una nueva literatura que buscaba como meta última la autonomía de la propia literatura y no la reivindicación de ningún interés extraliterario (político, social o cultural). La figura del escritor-militante representada por G. Aresti y "Txillardegi" en la época precedente cede paso a la de un creador que no obedece a motivaciones extraliterarias. Por otra parte, los cambios sociales y políticos ocurridos a finales de la década de los 60 y a mediados de los 70 en España (y consiguientemente en Euskal Herria peninsular) fueron notables. El Congreso celebrado por la Academia Vasca en 1968 en el santuario de Aránzazu (Oñate, Guipúzcoa) sembró la semilla de la unificación lingüística estableciendo las primeras bases de esta reforma.' Por vez primera, los vascos pudieron gozar de una lengua estándar o "koiné"que no pretendia menoscabar ningún dialecto y que estaba pensada especialmente para el uso del vascuence escrito, los medios de comunicación y la enseñanza. Además, en 1979 se aprobó el Estatuto de Autonomía, y en 1982 la Ley básica de la normalización del uso del euskara, que sirvió para impulsar la literatura vasca. La creación de nuevas editoriales como Lur (1969), Etor (1970), Gero (1971), Elkar (1972) y Erein (1976) favoreció en la década de los 70, la difusión de esta literatura.

Asimismo, en el País Vasco peninsular, tras la muerte de F. Franco el 20 de noviembre de 1975 , el fin de una dictadura de casi cuarenta años permitió la cooficialidad del euskara, la legalización de los partidos políticos y, en general, la aparición de nuevas libertades que hicieron posible, entre otros efectos saludables, la expansión de una nueva literatura vasca, importante en cantidad y calidad. El post-romanticismo y el simbolismo, que habían nutrido a la literatura

'El lector puede hallar más información sobre este tema en Sancho el Sabio, 1991 : 115-116 
vasca durante más de medio siglo, desembocaron en nuevas corrientes literarias como el "Nouveau Roman" francés (A. Robbe Grillet (1922 -) Nathalie Sarraute (1902 - ), Samuel Beckett, Claude Mauriac (1914 - 1984) ; en el realismo mágico hispanoamericano y en la literatura fantástica (J. Rulfo (1918 1986), J. L. Borges (1899 - 1986), J. Cortázar (1914 -1984), G. García Márquez (1927-), M. Vargas Llosa (1936 -), A. Carpentier (1904 - 1980), C. Fuentes, etc.). A diferencia de numerosos autores vascos que habían escrito anteriormente con criterios lingüísticos, o habían producido una literatura costumbrista de índole romántica, el grupo de los jóvenes escritores citados optó por la alternativa de una renovación profunda, poniendo el euskara al servicio de la nueva narrativa. La literatura tradicional, religiosa y, en gran medida, clerical, cedió paso a una literatura más moderna, y laica. Destaca en este grupo la preocupación por la búsqueda de soluciones estilisticas nuevas en las que las estructuras tradicionales del relato (tiempo, espacio, personajes, narrador omnisciente, etc.) quedarán desdibujadas. Ni la representación de la sociedad en la que se vive (realismo de H. Balzac), ni el estudio psicológico de los personajes (G. Flaubert), ni la intriga y el suspense serán en adelante el objetivo prioritario de la nueva narrativa vasca sino la condición exclusivamente verbal de la literatura, sin referencias extrañas al texto. De esta forma, desaparecerá, en gran medida, el relato lineal, la legibilidad continua de un sistema narrativo y la representación de los acontecimientos. En resumen, se quiebran las barreras formales y temáticas de la literatura vasca tradicional.

Por otra parte, asistimos en la década de los 70 a la aparición de tres revistas literarias vanguardistas que no gozaron de una larga vida, pero que influyeron notablemente en el estilo de futuros escritores en todo el País Vasco. Sus titulos fueron Ustela (Podrido) publicada entre los años 1975 -1976 en San Sebastián bajo la dirección de B. Atxaga, K. Izagirre y R. Saizarbitoria ; el grupo Pott (Desfal lecimiento) apareció entre los años 1978 - 1980 en Bilbao ;2 y Oh! euzkadi (1979 - 1983) publicada en San Sebastián por R. Saizarbitoria y K.Izagirre. ${ }^{3}$ Estos jóvenes escritores muestran su rebeldía estética : la transgresión verbal reivindicativa en pro de una autonomía radical de la literatura ; la necesidad imperiosa de escribir unida a la validez incuestionable del euskara para la creación de una literatura de calidad ; un espíritu rupturista, inconformista y radical, no exento de ironía, humor e ilusión ; un afán de modernidad propio de los escritores pioneros durante su época juvenil.

\footnotetext{
${ }^{2}$ Entre los fundadores hay que señalar a B. Atxaga, J. Sarrionandia, J.M. Iturralde, M. Frcilla, J. Juaristi y el cantante R. Ordorica. Entre los años 1978 y 1980 se publicaron seis números y los articulos aparecen indistintamente en euskara y en castellano. Los futuros derroteros de estos cinco artistas fueron muy divergentes. Así por ejemplo, J. Sarrionandia se convirtió en militante de ETA, huyó de la cárcel de Martutene (Guipúzcoa) y vive en el extranjero deleitando a sus lectores con sus nuevos libros, mientras que J. Juaristi ha preferido abandonar completamente el espiritu que inspiró al grupo Pott: "Euskal Jiteraturaz, Euskal Herriaz eta euskaraz aspertu naiz..." (Me he aburrido de la literatura vasca, del País Vasco y del Vascuence).("Y de perfil" en Zurgai 13, $1984: 27$ ). En cuanto al escritor de Asteasu, las divergencias surgidas entre B. Atxaga y $J$. Juaristi se pueden apreciar a raíz de una conferencia que el escritor guipuzcoano pronunció en mayo de 1993 en el "Forum Deusto" (Bilbao) en el que expresó su deseo de que desapareciera el grupo político "Unidad Alavesa". (El Correo 25-V-1993). J. Juaristi calificó de "impresentable" la charla de su antiguo compañero "[...] a quien estimo, o, más bien estimaba [...]."

${ }^{3}$ Oh! euskadi; se publicaron 16 números.
} 


\section{Bernardo Atxaga (1951 -)}

Joxe Irazu, "B.Atxaga", fue el escritor más representativo de este movimiento juvenil y ha mantenido siempre una coherencia ideológica con aquel espíritu renovador desde que en 1972 publicó su primer trabajo : "Borobila eta puntua" en un libro colectivo impulsado por G.Aresti, donde el escritor guipuzcoano usó por primera vez el seudónimo "B.Atxaga."4 Esa coherencia le ha movido a escribir preferentemente en vascuence (sin desdeñar nunca el castellano) por no traicionar su mundo afectivo : "escribo desde lo mejor que tengo, por eso lo hago en euskera." ${ }^{15}$ Entre sus cualidades más reseñables se nos muestra como lector empedernido desde la adolescencia ; como conferenciante muy solicitado y charlista infatigable ; como excelente narrador que capta al lector con numerosos símiles, analogías y juegos de palabras que le han convertido en referencia obligada de la renovación literaria vasca en el último cuarto del s. XX como un verdadero explorador del mundo de la ficción ; además de ser el escritor vasco más traducido en el extranjero, y el más leído en el País Vasco. En el aspecto personal se nos presenta como un humanista; sensible a las preocupaciones, sobre todo, de los perdedores y de los débiles ; trabajador incansable ; de talante inconformista, cordial e irónico ; dotado de una imaginación creadora y de una inteligencia aguda; sugerente y lúcido ; amante de la vida, de la libertad y del valor de la palabra.

B. Atxaga nació en Asteasu (Guipúzcoa) el 27 de julio de 1951. En su niñez estudió hasta los nueve años en la escuela de su pueblo natal pasando más tarde al colegio de los Hnos. de La Salle en San Sebastián, donde cursó el bachillerato. Pasa a vivir a Andoain desde donde toma contacto con centros urbanos cercanos como Tolosa y Villabona en cuyas bibliotecas halla libros de autores como los enciclopedistas franceses del s. XVIII ; los grandes novelistas del s. XIX : Ch. Dickens (1812 - 1870), L. Tolstoi (1822 - 1910), F. Dostoievski (1821 - 1881), H. Balzac (1799 - 1850), G. Flaubert (1821 - 1880), etc. ; y célebres autores del s. XX como M. Proust (1871 - 1922), F. Kafka, T. S. Eliot, W. Faulkner (1897 - 1962), R. Stevenson (1850 - 1894), H, Melville (1819 1891), J. Conrad (1857 - 1924), A.P. Chejov (1860 - 1904), G. Papini (1881 1956), M . Schwob (1867 - 1905), B. Brecht, E. Hemingway, G. Pérec (1936 1982) y otros escritores del grupo Oulipo (Ouvroir de Littérature Potentielle), etc. que sacian su pasión por la lectura. Con las maravillosas técnicas de éstos y otros autores, el joven, B. Atxaga fue templando su pluma para mostrar las luces y las sombras del corazón humano. A finales de la década de los 60 pasa a Bilbao donde cursa la carrera de Ciencias Económicas en la Universidad de Sarriko. Su interés por las aulas fue inferior al mostrado por las librerías y los cine-clubes. En cualquier caso, esta estancia en la capital vizcaína resultó muy interesante por su relación con el escritor G. Aresti de quien siempre se ha sentido deudor, y jamás ha ocultado su admiración y amistad. Mientras tanto, el panorama cultural y político durante los años 1968-1969 va cambiando notablemente en el País Vasco y se presienten los primeros estertores del franquismo. Junto al Congreso ya citado de Euskaltzaindia en Aranzazu (1968), la sociedad vasca se siente sacudida por sangrientos acontecimientos ocurridos cerca de Asteasu : la muerte de X. Etxebarrieta (militante de E.T.A.) y la del

\footnotetext{
${ }_{5}^{4}$ Se trata del libro Euskal literatura 72, Donostia, Lur 1992

${ }^{5}$ Deia 17-V-1992: 58
} 
joven guardia civil Antonio Pardines. ${ }^{6}$ B. Atxaga, tras finalizar sus estudios universitarios, consigue un buen empleo en un Banco de Donostia, pero lo abandona poco después, para dedicarse a su verdadera vocación : la lectura y la escritura, haciendo de su arte una profesión. Para poder sobrevivir buscaba todo tipo de trabajos (vendedor de periódicos, empleado en una imprenta y en una librería, profesor particular de lenguas y matemáticas, etc.) que le permitieran disfrutar del máximo tiempo libre $\mathrm{y}$, al mismo tiempo, de módicos ingresos económicos para poder subsistir. En 1983 marcha a Barcelona donde cursa la carrera de Filosofía que más tarde influirá positivamente en su creación literaria. En 1991 fue nombrado miembro correspondiente de Euskaltzaindia.

La producción literaria de B. Atxaga es extensa y variada. Abarca los campos de la poesía, novela, cuento y la abundante literatura infantil, con más de treinta libros.

\section{Primera obra : Ziutateaz (1976)}

A mediados de la década de los 70 , el joven escritor guipuzcoano rompía lanzas publicando su primer libro Ziutateaz que apenas tuvo eco, ni buena acogida por parte de los lectores por las dificultades que presentaba su estructura vanguardista. ${ }^{8} \mathrm{El}$ autor se muestra en él como un escritor "total" que narra valiéndose indistintamente de diversos géneros (poesia, teatro y narración). La crítica tradicional vasca, acostumbrada a la novela costumbrista, no supo valorar debidamente la obra de este pionero que se arriesgó a explorar por vez primera en la historia de la literatura vasca, una nueva forma de narrar mezclando diversos géneros y eliminando las fronteras convencionales que separan estos géneros. Respecto al tema, esta obra es homologable a otras novelas de afamados escritores (R. del Valle-Inclán, M. A. Asturias, M. Vargas Llosa, etc.) en las que se trata de la violencia institucional ejercida por un tirano. Esta obra publicada al año siguiente de la muerte del dictador F. Franco no está condicionada por unas coordenadas determinadas de lugar y de tiempo sino que entraña una estructura flexible y abierta, susceptible incluso de diferentes interpretaciones. Esta novela no perderá jamás su actualidad mientras permanezca un dictador en el mundo, pues sus ciudadanos no pertenecen a ningún país específico. Sin embargo no faltarán lectores que vean en esta novela alegórica la persona del dictador Franco en la figura de Scardenalli. En cualquier caso, se trata de una novela triste, lúgubre, desesperanzada, marcada desde el principio por el verso del poeta que maldice su nacimiento : "ai amaren haragia nitaz / inoiz erditu ez balitza."

La carga simbólica de la novela es evidente : la influencia de la literatura oral (el poeta Theo que vive en el muladar, el bertsolari Bilintx : "triste bizi naiz eta, hilko banintz hobe"(p.70); el teatro con el coro ; el anciano batelero Hyeronimus privado de la vista ; la región de los Ikaros (gente desposeída de sus derechos) presentada como un gheto sin otra salida más que la muerte ; el muladar al que está abocada a vivir la mayoría de esa región ; la metamorfosis del esquizofrénico Scardenalli que pasa, de ser un esclavo a actuar como el

\footnotetext{
${ }^{6}$ Hecho ocurrido el 7 de junio de 1968 en "Benta Aundi", Tolosa.

7 Junto a él entraron también en la Academia de la Lengua Vasca otros escritores conocidos como su amigo J. Sarrionandia. Euskera, 1991-2:693.

Bernardo Atxaga. Ziutateaz (2.ed.). Donostia, Erein, 1986: 153.

9 465. Ibid : 14.
} 
mayor verdugo de la ciudad, pues de la candidez de un ciervo pasa a la malicia de la serpiente.

Entre los personajes más importantes destacan el mencionado Scardenalli, Gómez, Antonín, y Joe, El primero de ellos llega a gozar de un poder absoluto pero es cobarde como lo fue su padre : "kobarde bat naiz nire aita bezela."10 Recurre hasta el asesinato para lograr el fin que se propone : ejercer la tiranía. Bajo su mandato, el ring de boxeo se convertirá en una especie de patíbulo en el que morirá el poeta Joe que ha vivido rodeado de libros pero que cae en desgracia, y al final de la obra será asesinado por los esbirros de Scardenalli. E1 tercer personaje, Gómez, es un reflejo del tirano principal pero carece de la maestría de aquél. Finalmente, la suerte de Antonín no es mejor porque de vivir feliz en un teatrillo, pasa a vivir a un parque zoológico donde vive sin libertad; acabará convirtiéndose en asesino y verdugo. Otros personajes secundarios como Max, M. Salat, Loiola, etc. ensombrecen el ambiente de esta novela necrofilica, llena de crueldad y desesperanza. En el fondo, el libro es también un canto a la libertad, una añoranza de este don tan preciado escamoteado por un dictador.

Para concluir el análisis formal, detallemos los tres géneros mencionados al comienzo de esta sección destinada a la primera novela de B. Atxaga. 1. Poesía : la parte dedicada a este género abarca cinco poemas que aparecen bajo el título de "Theo-ren Poemak" (pp. 19-24) ; otras dos poesías escritas en verso libre, y firmadas por el tirano Scardenalli, ocupan las páginas 57-58 ; una octava poesía (a modo de estrofa) se halla introducida en una parte descrita en prosa, titulada "Joe-ri jarraituz"(p. 101) y, finalmente, otras cuatro poesías muy breves cierran la parte dedicada al género poético (pp. 119-122). Éstas últimas no van encabezadas por ningún título y van dirigidas a una segunda persona. 2. Teatro : el segundo género literario empleado por el autor es el teatro; se trata de un teatro popular y no convencional en el que no existe el diálogo tradicional. El verdugo principal, Scardenalli, prepara una fiesta popular para ejecutar en la guillotina a Loiola, ejemplo del poder espiritual en la ciudad. El patíbulo provisional es una habitación oscura ("jokaleku beltz bat", p. 69) pero el patíbulo oficial estará colocado en el stadium de la ciudad sin nombre. Entre los personajes destaca el bertsolari "Bilintx" de cuyos famosos versos se hace una breve mención : "loreak udan ihintza bezala "(como la flor (ansía) el rocío en el verano", p. 73). 3. Narración : la parte más extensa de esta novela (pp. 25-56) está escrita en prosa y subdividida en cinco capítulos cuyo narrador es Scardenalli quien cuenta todo en primera persona. Cada una de estas cinco partes conserva su propia autonomía, como cada uno de los géneros mencionados, pero mantienen una unidad gracias a la figura del verdugo principal que sirve de hilo conductor de toda la obra.

\section{Poesía}

La producción poética de B. Atxaga no es muy amplia pues es autor solamente de dos poemarios : Etiopia y Poemas \& Hibridos. En más de una ocasión ha confesado además que le cuesta escribir poesía.

\section{Etiopia (1978)}

${ }^{10} \mathrm{Ibid}: 25$. 
Si la primera novela de B. Atxaga pasó casi desapercibida para el público, este segundo libro (primero de poesía) tuvo una gran repercusión a pesar de su hermetismo y del carácter vanguardista, siendo galardonado en 1979 con el Premio de la Crítica en el País Vasco. Este poemario se convirtió, además, en referente de la moderna poesía en Euskal Herria y ha tenido gran eco en la canción moderna. Probablemente ningún poemario publicado después de Harri eta Herri (1964) de G. Aresti, haya tenido tanta aceptación en la historia de la moderna poesía vasca como este libro del escritor de Asteasu.

"Ophelion ene anaiak eta biok zeharkatuak genituen jadanik Etiopia inguratzen duten harea ezberdinezko bederatzi zirkuluak. (Marcel Schwod)". ${ }^{11}$

(Mi hermano Ophelion y yo habíamos atravesado ya los nueve círculos de diferentes arenas que rodean Etiopía.)

El protagonista del poemario es un apátrida que, al igual que Caín (con cuya mención comienza el libro, p. 5) es un desterrado, arrojado del paraíso y obligado a deambular en un viaje a través de círculos desérticos en busca de una ciudad cuyos planos han quedado obsoletos. En esta ciudad, llamada Etiopía, cuyo acceso está obstaculizado por los mencionados círculos de arena, habitan seres humanos: los antihéroes tan queridos en toda la obra atxaguiana (barrenderos, borrachos, prostitutas, mendigos, un boxeador muerto, un aspirante a poeta que malgasta su tiempo buscando la belleza de bellas rimas, etc.). Algunos de los escritores citados por el autor optaron por el suicidio (G. de Nerval) o prefirieron abandonar completamente la poesía en la que creyeron firmemente para huir al desierto africano (A. Rimbaud). ${ }^{12}$ Estos escritores aparecen como los representantes lejanos de la moderna poesía por la ruptura total que defendieron contra la literatura que les precedió en el s. XIX como el romanticismo. El autor de Etiopia trata de seguir sus pasos afirmando desde el principio, con un símil clarificador, que ya no es posible hablar en primera persona empleando el yo romántico, ni escribir sobre temas favoritos de los autores románticos, como el amor, la soledad, la tristeza, la melancolía, el exotismo, la pasión, etc. : "ez dela posible lehen pertsonan mintzatzea." ${ }^{13} \mathrm{El}$ símil "hautsi da ANPHORA" representa la ruptura de un ánfora (imagen de unidad) que queda hecha añicos y simboliza tanto la desaparición de los valores tradicionales como de la estética poética que había prevalecido anteriormente en el romanticismo, simbolismo, parnasianismo, etc.

Etiopia muestra un poemario lleno de rebeldía y ruptura, que trata de transgredir las normas poéticas estereotipadas (como lo hicieron a comienzos del s. XX los dadaístas y surrealistas) suplantando el sentimentalismo romántico por las sensaciones ; las correspondencias y analogías platonianas por un tipo de poesía abstracta basada en la ironía ; susceptible de diferentes interpretaciones ; llena de metáforas insólitas e inesperadas ; escrita con una sintaxis atrevida y compuesta de "palabras libres" ; con referencias al mundo del cine (Humphrey Bogart, p. 90 o acabando el capítulo noveno con las palabras finales de las

\footnotetext{
${ }_{11}^{11}$ Bernardo Atxaga, Etiopia ( $3^{\text {a }}$ ed.), Donostia, Erein, $1984: 31$

${ }^{12}$ Sancho el Sabio. $2000, \pi^{\circ} 13: 25$.

${ }^{13}$ Etiopia: 99.
} 
películas americanas, "The end", p. 91) ; adornada con bellas sinestesias ; provista de una musicalidad lograda con el empleo de la aliteración ; plena de ternura pero, también, de dramatismo. Ahondando más en lo arriba expuesto hallamos imágenes originales de corte surrealista.

"larunbat honetan ekia ez da 220-60w gorbatadun

tigre funzionala, $[\ldots]$

Urrezko erloju paralitikoa larunbat honetan ekia

ezkilaz eta karameluz beteriko argi boltsa bat, [...]

(eztiz igurtziriko kaletan

haurrak bainila eta marrubizko soinekoekin.)". ${ }^{14}$

En ocasiones el tono dramático de una poesía va unido al juego de palabras logrado con la repetición de ellas : kutxilo, erdibitu, bihotza, zapustu, sehaska, lore, beltzez.

"Amaren bularrak ebaki zituen kutxiloaren ertzak

erdibitu egiten du semearen bihotza ere ;

erdibituriko bihotzetatik sortzen dira dere

Sehaskak zapuztuko dituzten hauster txoriek ;

zapuztu diren sehasketan bizi dira dere

kutxilo zorroztaileak [...]

aldare oro erori den erore

belaunaldiak lore beltzez katiatuaz,

birkatiatuaz lore beltzez eta iltzez lore". ${ }^{15}$

Con frecuencia el ritmo de los versos se asemeja a un pentagrama musical conseguido por medio de las aliteraciones (eia, eie eio, etc.)

"Begira egien berriro masustei,

Horma moriak egiten bideari [...]

Ainhoa ile beilegi,

Ispilu ttipiaz orrazten". ${ }^{16}$

En estas poesías no utiliza habitualmente la puntuación, v.g : "Eta trenek arrain biguina" [...], (p. 61) ; esto permite la posibilidad de múltiples interpretaciones diferentes conforme a la opinión de los distintos lectores.

La prueba del desgaste de la lengua (idea constante en los dos libros poéticos de B. Atxaga) es mostrada con frecuentes fórmulas gastadas con el uso corriente ("si-vuple", p. 23 ; "O-non O-non", p. 99" ; "comantalevu", p. 100 ; ma-o-meno", p. 87, etc.) Destaca también el número de expresiones, y de escritores extranjeros ("The end", "moito obrigado", "no comment", "my love", "off", "beautiful morning of", "oh, yeah, sleep", "for me, for you" ; M. Schwob, F. Picabia, G. Ungaretti, T.S. Eliot, Dante, etc. En cuanto a los escritores vascos sobresalen Axular, Etxahun, Duvoisin, Lauaxeta y Lizardi.

El desgaste mencionado de las palabras nos conduce a la crisis del lenguaje, a los clichés repetidos y al escepticismo sobre el valor de la expresión

\footnotetext{
${ }^{14}$ Ibid : 43 .

15 Ibid : 36 .

${ }^{16}$ Ibid : 55 .
} 
poética. Para evitarlo, el autor vuelve a la frescura de la literatura oral en su forma de canciones infantiles como el "Obabatxue" que aparece en el tercer círculo desértico de Etiopia. Se trata de una nana cantada en la provincia de Vizcaya.

"Obabatxue obabatxue

Obabatxue doian orduen

Zaldi urdinen gainean

Beste hainbeste mile gehiago

Joango dire atzean". ".

(A la hora en que el pequeño Obaba cabalga sobre caballos azules, otros tantos mil más irán por detrás)

Como conclusión, cabe decir que B. Atxaga trata de presentar la expresión renovadora de una poesía rupturista y liberadora que supera tanto los datos inmediatos como el empleo de símbolos y metáforas habituales hasta entonces en la literatura vasca.

\section{Poemas \& híbridos (1990)}

Se trata del segundo y último poemario de B. Atxaga, que contiene bellas poesias originales como "Trikuarena", pero también poemas que fueron publicados anteriormente en Etiopia ("Harearena", "Barkatu, Cravan", "Eguneroko bizitza", "Orduan", etc.). El libro está dividido en dos partes ; en la primera de ellas se hallan las poesías vascas con su versión castellana, (además de algunas otras que están escritas sólo en castellano). Esta primera parte es la que nos interesa para nuestro objetivo porque la segunda sólo contiene la traducción castellana de Henry Bengoa, Inventarium. La mencionada parte queda subdividida en tres secciones : once poesías vascas ; "Etxekoak" ; y "Kantak".

El libro arranca con la bella poesía "Trikuarena" (Del erizo). Se trata de un erizo que en su diccionario "universal" recuerda sólo unas 27 palabras. Durante más de siete milenios no ha variado su vocabulario; ni siquiera ha aprendido las palabras relativas a las luces de los coches y, en consecuencia, se expone a una muerte cierta al cruzar la carretera. Además, se mantiene adicto a su diccionario liliputiense ("hiztegi liliputiarra", p. 14), sin posibilidad de una evolución ulterior. Con mucho humor e ironía, B. Atxaga hace una apología cerrada a favor de la renovación del lenguaje como instrumento indispensable para la creación de un nuevo tipo de poesía : la parodia y el drama serán también armas constantes en su creación poética. La firme apuesta del escritor guipuzcoano en pro de la palabra renovada impedirá el desgaste y el anquilosamiento de las palabras, (debidos al uso multisecular de ellas), evitando de esta forma la creación de una poesía desvirtuada y polucionada que nos podría llevar al escepticismo. En consecuencia, urge la adaptación del euskara a la vida moderna.

"Zer, zer diozu Bihotz

Ez zaitut konprenitzen,

${ }^{17}$ Ibid : 51 . 


\section{Zure hitza arrotza zait, bitxia". ${ }^{18}$}

\section{(Qué dices Corazón}

No te comprendo

Tu palabra me resulta extraña, recargada.)

Al analizar Etiopia hemos mencionado la influencia de A. Rimbaud a quien B. Atxaga cita tanto en su prosa (p. 29) como en la poesía (p. 66). Gracias a varias referencias de otros autores, podemos comprender mejor el contenido tan hermético de la poesía del escritor guipuzcoano, así como detectar las influencias de diversos autores en estos dos libros de B. Atxaga. Los nueve círculos desérticos nos evocan el descenso del hombre moderno al infierno dantesco donde reina la marginación y la deshumanización. Otro tanto podríamos afirmar sobre el sentimiento de desamparo y soledad del hombre en la sociedad actual, al toparnos con uno de los personajes más representativos de la novelística de S. Beckett : Malone (Etiopia : p.99). Para este escritor dublinés, afincado en París, el lenguaje se va descomponiendo progresivamente y asistimos a la irrisión de la lengua cotidiana, incapaz de percibir la visión trágica del mundo. La palabra, como instrumento de comunicación, se convierte en soledad en este mundo absurdo y carente de sentido. ${ }^{19}$

Además, aunque no aparece ninguna mención explícita del nombre del escritor austríaco Georg Trakl (1887-1914), su influencia es también manifiesta tanto temática como estilísticamente en la obra poética del escritor de Asteasu. ${ }^{20}$ La siguiente estrofa es una simple prueba de lo que afirmamos.

"Zeit, Einsamen Helian,

Abens grauen flammendes,

Ez zaitut konprenitzen, oi ene Bihotz". ${ }^{21}$

${ }^{18}$ Bernardo Atxaga. Poemas \& híbridos. Madrid,Visor, $1991: 70$.

19 Samuel Beckett nació el 13 de abril de 1906 en Dublín. En 1938 se estableció en París, participando activamente en la Resistencia francesa durante la II Guerra Mundial. Cultivó diversos géneros : poesia, ensayo, teatro y novela, obteniendo el Premio Nobel de literatura en 1969. Se le considera como uno de los grandes creadores del teatro del absurdo, junto con Ionesco, Adamov, etc. Entre sus obras más conocidas se hallan Murphy (publicada en inglés en 1938 y traducida al francés en 1947), Molloy (1951), Malone meurt (Malone muere, 1951) y, sobre todo, su pieza teatral En attendant Godot (Esperando a Godot, 1953) en la que dos vagabundos (Vladimir y Estragón) esperan en vano una solución que liegue del cielo. En el drama de la vida humana concurren la miseria, el miedo y la espera inútil de una posible solución que no llegará jamás pues "no pasa nada, nadie viene, nadie se va". Con esta obra este escritor irlandés, renovó radicalmente la estética del teatro de la segunda mitad del siglo $\mathrm{XX}$.

${ }^{20}$ Georg Trakl nació en Salzburgo el 3 de febrero de 1887. Ya desde su adolescencia se le veía marcado por la adicción a las drogas, su inclinación al suicidio, y, más tarde, por la relación incestuosa con su hermana Grete que en 1915 acabará suicidándose en Berlín de un disparo. En su juventud abusaba de la bebida, las drogas y frecuentaba los burdeles, sufriendo fuertes ataques y períodos depresivos que le condujeron al psiquiátrico. Tomó parte como teniente enfermero en la I Guerra Mundial (1914-1918) a favor de las tropas austro-húngaras. Toda la miseria de la humanidad se le quedó grabada durante el período bélico, condicionando en gran medida su poesía. A medida que fueron pasando los años, se fue agudizando el conflicto familiar con su madre a la que deseó matar. El miedo a la locura y a la muerte de los últimos años le condujeron el 3 de noviembre de 1914 al fin de su vida, por una parada cardiaca ocasionada por una sobredosis de cocaina. Entre las numerosas influencias literarias que aparecen en su obra destacan las de A. Rimbaud, Hölderlin, Nietzsche, E.A. Poe y Heine. Georg Trakl. Obras completas, Madrid, Ed. Trotta, 2000: 9-58.

${ }^{21}$ Poemas \& hibridos: 70. 
Varias de las ideas fundamentales del pensamiento poético del genial escritor de Salzburgo aparecen, sin duda alguna, en los dos libros poéticos de B. Atxaga : la crisis del lenguaje convertido en puro concepto ; "el yo insalvable" o el sometimiento del yo explícito ; la literatura como utopía contra una sociedad deshumanizada ; el anhelo de libertad ; la eliminación de esteticismos suplantados por formas más severas ; la presentación de una realidad desnuda (compárese por ejemplo, "las ratas gigantes de la ciudad" de Etiopia (p. 83) con las ratas que "casa y granero corretean") del escritor austríaco ;22 la presencia del personaje Helian en la obra poética de ambos escritores; el ansia de crear una nueva poesía ; la negación de valores mantenidos como inmutables por el racionalismo ; el enfrentamiento con la cultura burguesa que ha convertido el lenguaje en puro concepto ; la identificación de ambos escritores con los marginados de la sociedad, los pobres, las prostitutas, los locos, etc.

Doce años más tarde, en los cursos de verano de 1990 en San Sebastián, B. Atxaga recordó sus años de juventud en los que traslucía un exceso de agresividad, y la influencia de las vanguardias que le impidieron una mayor reflexión y la búsqueda de otras formas de poesía.

\section{Narrativa. Novela}

\section{Bi Anai (1985)}

El título del relato Bi Anai (Dos Hermanos) viene dado por los dos protagonistas principales. Este libro podría ser considerado como un segundo punto de partida de una larga trayectoria literaria de trece años (1972-1985.) Es irrelevante indagar si se trata de una novela corta o de un cuento largo ; lo que realmente interesa, es constatar que el autor se adentra en el mundo de la literatura fantástica apartándose de los estrechos márgenes del realismo. Dejando de lado la causalidad lógica y apostando por la causalidad mágica, el autor abre una brecha entre la razón y la fantasía para mostrar una visión distinta en torno a las realidades ocultas. B. Atxaga explora aquí las ricas potencialidades de un relato prestando voz (como en las fábulas) a los animales. Este recurso es empleado sistemáticamente en esta obra (como en varias otras de sus novelas posteriores) valiéndose de una polifonía de voces, y de personajes simbolizados por diversos animales. Desde el interior de estos personajes surge una nueva realidad ; una simbiosis entre la fantasía y la realidad, sin distinción de márgenes entre lo real e irreal. En concreto, unos hechos reales, crueles y trágicos son narrados en esta obra, pero creando a la vez nuevos mundos metafóricos y simbólicos. La historia real de dos jóvenes hermanos que acaban al final de la novela desapareciendo convertidos en dos ocas, refleja un mundo cruel en el que el inocente se convierte en culpable y es castigado, como si fuera una bestia, por una sociedad inmisericorde. Un ambiente de soledad, fracaso, violencia, sexo, impotencia, etc. ensombrece la vida de los personajes convirtiéndolos en víctimas unos de otros. Un destino cruel e inexorable condiciona la vida de los personajes y de los animales que viven su tragedia : la serpiente mata al pájaro (p. 87) pero a su vez muere con la cabeza aplastada por la oca (p. 106). Las ardillas mueren de pena. El análisis del

${ }^{22}$ G. Trakl. Obras completas, (2a. Ed.), Madrid; Trotta, $2000: 84$ 
argumento, estructura, personajes, estilo, lenguaje, etc. nos permitirá comprender mejor esta novela que viene a ser como un anticipo de Obabakoak.

\section{Argumento}

El libro comienza con una voz interior "Bada mintzo bat barnetik sortzen zaiguna" (existe una voz que surge del interior de nosotros mismos). ${ }^{23}$ Esta voz ordena a un pájaro dirigirse al pueblecito de Obaba para visitar a un muchacho de 15 años, llamado Paulo. Antes de morir el padre, Paulo había sido requerido por su progenitor para que se hiciera cargo del hermano mayor, Daniel, adolescente de 17 años, y retrasado mental desde su nacimiento. La difunta madre, María, se había sentido culpable y vivió abatida hasta la muerte, viendo en la enfermedad del hijo un castigo de Dios. Por otra parte, la madre, dueña de un aserradero, temía que sus familiares (padres de Carmen) se apoderaran de la empresa, y antes de fallecer ordenó que no se les permitiera entrar en su casa. Esto provocó una ruptura familiar y el consiguiente odio en Carmen que pretendía ir a vivir junto a su primo Paulo. Mientras éste se hace cargo del aserradero, Daniel se divierte jugando con las ardillas y degustando los pasteles que unas chicas de una repostería regalan a los niños de Obaba. Daniel se pasa las horas junto a la ventana del taller de costura contemplando a una joven llamada Teresa quien le permite ciertas libertades sexuales para atraer, de esta forma, al hermano menor : "hamazazpi urte dizkin baina zirri egiteko hogeitazazpi balitu bezela." ${ }^{24}$ (Ha cumplido diecisiete años pero para realizar tocamientos, es como si tuviera veintisiete). Con ocasión de una carrera de cintas en las fiestas de Obaba, Carmen intenta vengarse de Paulo y prepara una treta. Pone una anilla muy pequeña a la cinta destinada a Daniel para que éste, montado sobre una bicicleta, no pueda alcanzarla. Fracasa en el intento y cae al suelo, mientras que otro niño la consigue provocando la cólera de Daniel quien maltrata al campeón hasta herirle. El público exige a Paulo que mantenga a su hermano encerrado en casa atado como si fuera una bestia. Al final de la novela, ambos hermanos se dirigen a la vía del tren, cercana al pueblo. Al pasar aquél sobre los dos hermanos, aparecen dos ocas que unidas a una bandada de gansos vuelan hacia el sur.

\section{Estructura}

El papel de narrador es atribuido a " Mintzoa" o voz interior y a cuatro animales : el pájaro, la ardilla, la serpiente y las dos ocas. B. Atxaga se vale de este nuevo recurso formal, habitual posteriormente en sus escritos de ficción. Esta voz interior se constituye en narrador omnisciente del destino de los distintos personajes de la novela, así como en centro de toda situación narrativa especialmente en el capítulo séptimo. Los mencionados animales se atribuyen respectivamente a varias personas : pájaro - Paulo, ardilla - Daniel, serpiente Carmen y las dos ocas - Daniel y Paulo. El pájaro toma parte muy activa en los capítulos (1, 2, 3, 5, 6 y 9). La ardilla actúa en un grupo de seis ardillas y necesita de la información de "Mintzoa" quien le dicta cómo debe actuar. Narra en primera persona y actúa en los capítulos $(1,4$ y 6$)$, especialmente en el cuarto. La serpiente aparece en los capítulos $(8,10,11$ y 12). Este reptil (con las connotaciones que conlleva la serpiente) sale siempre a favor de Carmen. Es (después del pájaro) el animal que más actúa.

\footnotetext{
${ }_{23}^{23}$ Bernardo Atxaga. Bi anai, (5 ${ }^{\mathrm{a}}$ Ed.), Donostia ; Erein, $1990: 7$.

${ }^{24}$ Ibid. : 41.
} 


\section{Personajes}

Paulo. Es el primer referente humano que hallamos en la novela (p. 10) Aparece como antihéroe que no acierta a adecuarse al mundo de los mayores. Se muestra como cabeza de familia y responsable de su hermano mayor en casi toda la novela.

Daniel. Al comienzo del relato aparece juguetón como las ardillas que le representan. Pero a medida que avanza la obra va mostrándose como un monstruo deforme : casi sin pestañas, no controla sus funciones primarias, huele a orina, se masturba "hazia ixuri zuen galtzetan" (p.42) ; se discute incluso sobre la conveniencia de tenerlo atado como a un perro.

Carmen. Es un personaje complejo. Se diferencian dos etapas en su vida ; la de su niñez en la que se muestra como una niña normal y la de su juventud en la que aparece vengativa, tramposa, astuta, manipuladora, violenta y mala. Un lunar enorme que afea su rostro, se convierte en el mejor símbolo de este personaje marcado por la frustración.

Teresa. Es el medio utilizado por Carmen para llevar a cabo su venganza ; es manejada a su antojo por ella. La afectividad y su cariño hacia Paulo son las notas más destacables de este personaje no tan importante como los tres anteriores. Es la única que conoce el lugar al que huyen ambos hermanos al final de la obra.

Otros personajes como los padres de Daniel y Paulo ; el colectivo del pueblo de Obaba y el cura : "beltzez jantzitako gizona" (un hombre vestido de negro), expresión repetida insistentemente en el relato, se manifiestan como representantes y controladores del orden social.

\section{Coordenadas espacio-temporales}

Como hemos anunciado anteriormente a lo largo de este análisis el relato se desarrolla en Obaba, pueblecito de cien casas. Se trata de un lugar geográficamente indeterminado, imaginario, mítico y fantástico como lo fueron v.g. : Macondo en la obra literaria del escritor colombiano G. García Márquez o Comala en la del mexicano J. Rulfo. Sólo sabemos que Obaba se halla situado en una zona montañosa, cercana a una vía férrea, y que cerca de él pasa un riachuelo. Otros detalles como la existencia de una iglesia con su torre, un aserradero, una fuente y un taller de costura configuran el cuadro de este pueblo.

En cuanto a la coordenada tiempo, conviene señalar que éste transcurre en un período que abarca varios meses, desde el comienzo del verano hasta el otoño, época de la emigración de las aves. La analepsis, flash back o el carácter retrospectivo es frecuente en esta novela, rompiendo así el orden cronológico sucesivo del relato para narrar acontecimientos ocurridos en un tiempo anterior al momento en que se halla la historia v.g. : las diferencias entre las dos familias de los protagonistas (Paulo-Carmen) o la muerte de los padres de aquél, etc. A pesar de ello, el relato mantiene un carácter lineal desde el principio hasta el final. La dislocación espacio-tiempo será una técnica muy usada en la futura literatura de B. Atxaga. 


\section{Estilo}

En cuanto a las figuras retóricas de este libro convendría destacar su carácter simbólico pues podría afirmarse que toda la obra se transforma en una gran metáfora que atrae al lector por su belleza. Por otra parte, las comparaciones son frecuentes y muy descriptivas ; propias de un autor que conoce bien el entomo rural. Como muestra, cito dos ejemplos utilizados para describir los andares y gestos de Daniel : "umeak eginberri dituen zerrama batek bezala zeharkatzen zuen buru haundiak zubia". (p. 91). ${ }^{25}$ (El cabezón (Daniel) atravesaba el puente andando como una cerda que acaba de parir) ; o "euliak uxatu nahi dituen idi batek bezala eragin zion buruari". ${ }^{26}$ (Movió la cabeza como un buey que intenta ahuyentar las moscas). Destacan también las repeticiones logradas con nombres propios: (Paulo, p. 61) ; verbos : (ahantzi, p. 92) ; sustantivos: (izar, p. 28), (iturri, p. 86), (udara, p. 33), etc. En cuanto a los diálogos, sobresale el mantenido entre Carmen y Teresa en el capítulo VII. En el apartado gramatical es sorprendente el número de vocablos tomados de los dialectos de Euskal Herria continental v.g. : bertze, elki, petizione, bozkario, mintzo, alderat, anitz, ediren, libro, tenore, igorri, aitzina, erran, ahantzi, oro, igurikitu, etc., que embellecen el vascuence unificado del escritor de Asteasu.

En cuanto al tipo de euskara empleado por B. Atxaga en este libro, así como en sus primeros cuentos, no faltarán escritores que hallen errores gramaticales y lingüísticos. Así, por ejemplo, Andolin Eguzkitza, académico de Euskaltzaindia, muestra algunas expresiones y una larga lista de vocablos que, según la Academia Vasca, no son correctas. ${ }^{27}$ Con todo, aun aceptando como válidas estas observaciones, el consenso en cuanto a la calidad literaria de este libro, y, en general, de toda la obra del escritor de Asteasu, es unánime. Bernardo Atxaga ha sabido crear su propio y bello estilo literario, además de usar un vascuence funcional y práctico para reflejar el mundo moderno, cumpliendo de esta forma, el deseo del primer escritor vasco, Bernardo Detxepare : "Heuskara jalgi hadi kanpora!" ( jalgi adi mundura!" (Euskara, sal al mundo)

Finalmente, es sorprendente el uso que B. Atxaga hace de los recursos que le proporciona la literatura oral. Admirador del vascuence que le legaron sus paisanos de Asteasu (J. B. Agirre, Pello "Errota" y su hija Mikaela Elizegi), el autor se vale, en este libro, de elementos narrativos de la literatura oral pertenecientes al mundo del bertsolarismo obteniendo expresiones idénticas a las originales, excepto la nueva grafia recomendada por Euskaltzaindia. Como muestra presentamos un ejemplo.

Ibid. : 91

${ }^{26}$ Ibid. : 85 .

${ }_{27}^{27}$ A. Eguzkit.a, "Literatura hizkuntza, defentsa bat", Jakin, ñ 48, $1988: 149-154$.

28 Para mayor información presentamos el articulo "Obabakoak" del escritor Pello Esnal en Zutabe 18, $1988: 84-88$. 
M. Elizegi

"Arek ala esan omen zuan :

- Gona zar bat adabatuko litzake

bañan au ez, neskatxa, au ez [...]

Egun baten, anayak leiotik baratzara

begira eta negarrez arkitu zuan,

ala galdetu zion :

- Zer den Dolorex?

Ta arek:

- Ez diat ezer ere, bañan

pentsatzen natxiok aurki lur orren

azpira joan beharrean nagoala

emeretzi urterekin..."

\section{B. Atxaga}

"Eta medikuak hala esan omen zuen :

- Gona zahar bat adabatuko litzateke

baina hau ez, neskatxa hau ez.

Egun batean, anaiak leihotik baratzara

begira eta negarrez aurkitu omen zuen,

eta hola galdetu :

- Zer dun arreba?

Eta berak :

- Ez diat ezer ere, baina

pentsatzen niagok aurki lur horren

azpira joan beharrean nagoela

hemeretzi urterekin..."

\section{Obabakoak (1998)}

La capacidad narrativa y mitificadora de Bernardo Atxaga llegó a su cenit con Obabakoak (Los de Obaba). El libro no describe esta aldea montañosa, pero cuenta las historias ocurridas en ella y su paisaje afectivo ; geográficamente indeterminado y mítico. El origen del título proviene de los primeros sonidos labiales (ba-ba) de cualquier bebé. Los lectores se rindieron fascinados ante el encanto de este libro que puede ser considerado como su primera gran novela y una de las grandes obras en la historia de la literatura vasca. La acogida que se le dispensó fue muy favorable como puede observarse por los premios obtenidos. Por primera vez una obra escrita en euskara logró el reconocimiento estatal siendo galardonada con el Premio Nacional de Narrativa (1989) ; con el Premio Euskadi de Literatura y el de la Crítica, además de ser finalista para el premio "European Literary Prize", instituido por la comunidad Europea, y fallado el 26 de noviembre de 1990 en Glasgow. Más aún, ha sido traducida a más de veinte lenguas extranjeras, hito que no había alcanzado anteriormente ningún otro libro escrito en euskara. Cabe preguntarse por la razón de este reconocimiento oficial. ¿Qué encierra este libro para lograr tan favorable acogida? Nos estamos refiriendo, sin duda alguna, a su carácter de "antinovela" que no acata el decálogo de la novela tradicional anquilosada en el pasado. Obabakoak supone la culminación de una larga historia de logros obtenidos, merced a los esfuerzos vanguardistas y transgresores de su autor durante dieciséis años (1972-1988). Ellos dieron su fruto que se plasmó en este fascinante libro descrito por B. Atxaga como "una red de historias". Se trata de una "antinovela" tejida con varios relatos interrelacionados, algunos de los cuales fueron premiados y publicados con anterioridad. El autor lo describe de esta forma : "Un proceso de diez años. Muchos trabajos reescritos. Mi única dedicación en estos tres años. Historias dentro de otras historias, personajes entremezclados. En los límites, en el filo."29

${ }^{29}$ Gaur express. Junio 1989. VIII-32. 
La prosa elegante, y fascinante, ágil y profunda, tierna y bella de B. Atxaga está creada por diversas técnicas : el uso de elementos cultos de la tradición europea y universal, junto a otros elementos de la tradición oral. Este libro es como un viejo arcón de caserío donde se pueden hallar diversos materiales literarios : leyendas, cuentos populares, rasgos autobiográficos (especialmente en los cinco primeros cuentos) ; reflexiones sobre la teoría de escribir, sobre la forma de plagiar, sobre la metaliteratura, sobre las lecturas, sobre la memoria, etc. En definitiva, se trata de un microcosmos literario en cuyo lenguaje se combinan elementos variados que van desde el humor a la melancolía, desde la realidad a la fantasía, desde lo universal a lo particular, desde la historia a la ficción, desde la violencia a la ternura, desde la soledad y la muerte al nacimiento de una literatura euskérica, sutil y mágica.

La destreza tan personal y singular mostrada por el autor está lograda por el distanciamiento con respecto a la novela tradicional y convencional (planteamiento, nudo, desenlace) y al pensamiento racional y lógico. B. Atxaga apuesta por una creación literaria libre e inspirada en lo irracional y ficticio, como origen de una literatura creadora y singular, propia de un escritor novedoso al estilo borgiano. Hechos tan inverosímiles como la transformación de un niño en jabalí blanco (comienzo de esta novela) o la introducción de un lagarto en el oído de una persona (final de la misma) son presentados con idéntica verosimilitud que las descripciones de la novela tradicional del francés H. Balzac (vg : Le Père Goriot, 1834) ; del castellano J.M. Pereda (Sotileza, (1885) y Peñas Arriba (1894)) o del vasco Tx. Agirre (Kresala (1906) y Garoa (1912)). La montaña y el mundo rural de las novelas atxaguianas, poco tienen que ver con Auñamendi y las novelas idílicas, bucólicas, costumbristas (rurales o costeras) del escritor ondarrés. Las descripciones pormenorizadas y realistas de personas, lugares y objetos no caben en esta narrativa en la que los personajes no presentan la entidad de realidades físicas. La finalidad última que busca $B$. Atxaga no es la descripción de los acontecimientos sino el hecho mismo de escribir, la metaliteratura (la escritura sobre la palabra). El autor narra hechos simples y sencillos combinando la fabulación con la expresión realista en un entorno ficticio, y en un tiempo proustiano en el que la cronología no existe o es discontinua. Consecuentemente, la noción del tiempo pierde el sentido funcional de la novela tradicional. Además, los episodios que se narran en el libro abarcan una duración de varios siglos desde la Edad Media hasta la época contemporánea.

Obabakoak está compuesto por veintiséis cuentos comprendidos en 402 páginas. Son narraciones aparentemente independientes; algunas de ellas fueron publicadas anteriormente, vg : el primer cuento "Camilo Lizardi erretore jaunaren etxean aurkitutako gutunaren azalpena" (Exposición de la carta hallada en la casa del señor párroco Camilo Lizardi) publicado en 1982 y galardonado con el "Premio Ciudad de Irún". Obabakoak posee una estructura tripartita en la que la primera parte abarca cinco narraciones. La segunda contiene un solo cuento : "Hamaika hitz Villamedianako herriaren ohoretan eta bat gehiago" (Once palabras en honor del pueblo de Villamediana y una más), que hace de puente de unión entre la primera y tercera partes siendo además, el cuento más extenso de esta novela. La tercera parte : "Azken hitzaren bila" (En busca de la última palabra) comprende veinte 
cuentos ; conserva, además, una autonomía propia y podría ser considerada como una novela corta en la que la ficción resalta como única realidad.

Primera Parte. Sus cinco cuentos están relacionados directamente con el pueblo de Obaba, considerado como un espacio de evocación mágica y no como un lugar físico. En ellos se acumulan muchos recuerdos de la infancia del autor, vividos en su Asteasu natal, y narrados con mucha fantasía. En el plano estilístico, nos hallamos ante un ensayo de exploración del hecho narrativo. Ya desde el primer cuento "Camilo Lizardi erretorearen etxean...", el autor sorprende al lector con el uso de diversos recursos, como el empleo variado del euskara ; este cuento está escrito en vascuence unificado pero conlleva una parte considerable narrada en el dialecto guipuzcoano clásico del s. XIX.

El argumento y, sobre todo, la estructura del mencionado relato pueden servir de pauta para comprender, en gran medida, el resto de la primera parte de la novela. El punto de partida arranca con el hallazgo de una carta encontrada por el narrador. El mencionado documento escrito en 1903 por un párroco, contiene once hojas de las que algunos párrafos son ilegibles por el deterioro causado por la humedad del sótano en el que han permanecido durante muchos años. Es un escrito que el cura preparó para enviárselo a un amigo suyo pero que quedó sin remitirlo. Estas hojas narran varios hechos ocurridos en Obaba : un niño huérfano (Javier) es maltratado por la gente del pueblo con la excepción de su buen amigo, el anciano Matías. Se cuenta, además la metamorfosis de Javier convertido en un jabalí blanco, y se silencia su filiación relacionada con el cura, sugerida por el transcriptor tan sólo al final de la narración. Camilo Lizardi escucha un tiro, y tras seguir al jabalí malherido le oye proferir tres veces la palabra "ama" (madre) antes de que éste expire junto al cadáver de Matías. El sacerdote remata con una piedra la faena que el anciano había comenzado con una escopeta. El narrador de este cuento actúa como transcriptor de la carta descubierta en el sótano.

El cuarto cuento de esta primera parte titulado "Esteban Werfell" merece también una atenta consideración por su extensión (pp. 69-109) y las características especiales que concurren en él. Si hasta ahora Obaba habia sido el lugar más importante de la narrativa de B. Atxaga, en adelante esta aldea rural combinará con Hamburgo, una de las metrópolis europeas más famosas. La coordenada de lugar (Obaba-Hamburgo) es destacable para comprender el vínculo existente entre la ficción y la realidad que se entrelazan estrechamente en algunos momentos. Así por ejemplo, los nombres de las calles de la ciudad germana son reales mientras que los puntos de referencia de Obaba quedan desdibujados. Además, la dicotomía geográfica Obaba (aldea, bosque) - Hamburgo (urbe, cultura) es constante en varios pasajes del relato. Por otra parte, una de las reflexiones del autor acerca del concepto del tiempo ("bi denbora mota", p. 104) podría facilitar al lector la comprensión de este dificil relato. B. Atxaga distingue el tiempo histórico y cronológico (que él llama "arrunta" = ordinario o común) del tiempo "erratua" o de los sueños. 
El tema de este relato se relaciona con un memorándum que el protagonista Esteban escribe sobre el ficticio descubrimiento de una joven alemana, María Vöckel, a quien recuerda desde un desmayo que sufrió a los catorce años en el coro de la iglesia parroquial de Obaba. Tras el discurrir de los años, en el otoño de su vida, Esteban (gracias al viaje realizado a Hamburgo) constata el engaño al que le sometió su padre. En realidad, jamás existió su Maria Vöckei, y todo fue tramado por su progenitor (con la connivencia de un viejo amigo suyo, Theodor Volge, que vivía en Hamburgo) con el fin de que Esteban abandonara Obaba para acudir a la universidad y educarse en la cultura germana. La extensa y supuesta correspondencia mantenida entre Esteban y la señorita alemana se reducía, en realidad, a unas cartas escritas por su padre en Obaba y enviadas a Hamburgo, para que desde allí (previa la trascripción hecha por una adolescente) fueran remitidas a Esteban. En el plano estructural, el hecho del desmayo del adolescente Esteban y la aparición de M. Vöckel narrados en la primera parte del relato, se combina con el hecho de la escritura del memorándum que el protagonista redacta en Obaba a la vuelta de su viaje a Hamburgo. Ambos eventos se superponen, interrumpiéndose y retomándose constantemente, obligando, de esta forma, al lector a una lectura atenta y detenida. Por otra parte, no faltan pasajes en los que afloran el humor y la ironía, como en la conversación mantenida entre el padre y el hijo acerca de la relación amorosa con la adolescente germana y la consiguiente comparación entre el mal de amor y un dolor de muelas. "Maitasunaren minak eta haginekoak berdinak dituk, Esteban. Biziak oso, baina sekula ere ez grabeak" ${ }^{130}$ (Los dolores causados por el amor son como el dolor de muelas; intensos pero no graves).

Segunda Parte : "Hamaika hitz Villamedianako herriaren ohoretan eta bat gehiago" (Once palabras en honor del pueblo de Villamediana, y una más). Esta segunda parte ofrece una historia narrada sobre escenas rurales y ambientada en Villamediana, pueblecito castellano de 200 habitantes, cercano al rio Pisuerga en la provincia de Palencia. Es además, la parte más autónoma de la novela y queda un poco desconectada del resto de ella. Además, los once relatos mantienen una unidad a pesar de la autonomía de cada uno de los cuentos, pues todos ellos se desarrollan en un espacio común y están elaborados con recursos narrativos comunes. La mencionada segunda parte consta de una introducción y de once cuentos interrelacionados. El pórtico introductorio está formado por dos secuencias que presentan el tema de la memoria a través de dos casos de enajenación mental. En el primero de ellos, la locura ha sido causada por la incontinencia verbal, efecto, a su vez, de una prodigiosa memoria del paciente : "[...] gizonak bertan segitzen zuen, etengabe hitzegiten [...]. Gauza gehiegi gogoratzen zaiola" (pp. 124-125). Veinticinco años más tarde, aparece otro caso de trastomo mental. El paciente (Martín) ha perdido completamente la memoria : "Oroimenik ez dauka", (p. 127). Estos dos casos permiten al narrador reflexionar sobre la facultad de la memoria, comparándola con una presa y advirtiendo de los posibles riesgos que conlleva ; conviene recordar, pero no excesivamente. El propio relato, el hecho de la escritura, será el objetivo principal de toda esta segunda parte.

${ }^{30}$ B. Atxaga. Obabakoak, Donostia, Erein, $1988: 101$. 
"Nik uste dut oroimena presa bat bezalakoa dela [...]. Bizitza ematen dio gure izpiritu osoari, erregadiatu egiten du, nolabait esateko. Baina presari bezala, behearrezkoak zaizkio sangragerak - ihispideak - gainezka ez egiteko. Ezen gainezka egiten badu, edo lehertu egiten bada, txikituta uzten ditu inguru guztiak."

(Pienso que la memoria es como una presa. Da vida a todo nuestro espiritu; para decirlo de alguna forma, lo riega. Pero, al modo de una presa, necesita de unos aliviaderos para no desbordarse. Porque si se desborda o se revienta, deja destrozado todo lo que halla en su entomo.)

El narrador cuenta las primeras vivencias sobre el pasado, esto es, su historia personal desde que era un niño de nueve años : "bederatzi urtetako haurra besterik ez nintzela"(p. 123), consignando de esta forma sus recuerdos del pueblo de Villamediana. Se trata de un narrador omnipresente en toda la narración, innominado, sin rasgos físicos reseñables, y originario de una tierra diferente de la meseta castellana a la que llegó huyendo de sus propios "musgos y helechos interiores". En su vida diaria de casi un año en Villamediana destacan tres hechos : la llegada, la larga estancia y la despedida. Es un observador culto, sociable y curioso que trata con las diferentes personas que habitan en este pueblo semidesierto convertido en un "lugar de sombras, fantasmas y silencio". Se interesa no sólo de los problemas laborales de esta gente (pastoreo, labranza, cosechas, caza, etc.) sino de muchos temas relacionados con la literatura: (Hesiodo (s. VIII a.J.C), L. Góngora (1561 - 1627), B. Pascal (1623-1662), M. Montaigne (1533-1592), J.J. Rousseau (1712-1778), Pérez Galdós (1843 - 1920), Unamuno, Stevenson, Faulkner) ; con la historia (Felipe IV) ; con la mitología (Caliope, Dafnis) ; con la política (B. Mussolini (1883 - 1945), J. D. Perón (1896 - 1974); con la filosofía (Aristóteles), etc.

Villamediana es un pueblo triste y sombrío, carente de niños y de gente; la mujer más joven tiene unos cuarenta años. Se asemeja a un ghost town del Oeste americano por el número elevado de casas abandonadas. El desarraigo, la soledad, el aislamiento, la marginación, la vejez sin cariño familiar, y la falta de un futuro esperanzador son patentes en este pueblecito donde sólo hay dos bares, tres tiendas y doscientas personas. Entre sus moradores (pastores y labriegos, en la mayoría de los casos) destaca el mundo de los ancianos y marginados : Carlos García, alias Enrique de Tassis, arquetipo del poeta maldito ; los ancianos Julián, Benito y Crisanto (vecino del narrador); el viejo pastor Gabriel ; la tendera Rosi, alias Rita Hayworth ; el cazador Agustin, etc. A pesar de vivir aislados y marginados no faltan (entre esta gente de la meseta castellana) personas a las que el narrador trata con amistad y ternura. Son Enrique de Tassis que es un fino poeta y un lector culto (interesado más en etimologías que en símbolos) a pesar de su enanismo y de la

${ }^{31}$ Ibid. : 128. 
marginación en la que vive ; el viejo pastor Gabriel evoca al Arcángel San Gabriel ; los ancianos Julián y Benito son respetados y queridos por su bondad, etc.

Tercera Parte. "Azken hitzaren bila" (En busca de la útima palabra). Esta tercera parte es la más compleja de todo el libro no sólo por su extensión (veinte cuentos, pp. 199-403) sino también por los diferentes registros literarios (intertextualidad, sueño, ironia, reflexiones metaliterarias, elogio del plagio,fusión de realidad y ficción, uso frecuente de expresiones inglesas, etc.) y por la diversidad de los relatos. Su título, la búsqueda de la última palabra, es el elemento aglutinante que cohesiona esta larga lista de cuentos entre los que destaca "Ondo plagiatzeko metodoaren azalpen laburra eta adibide bat" (Breve explicación del método para plagiar bien y un ejemplo). En este último cuento B. Atxaga hace una apología cerrada de la lengua vasca valiéndose del relato de un sueño, a la vez que explica su postura personal sobre el plagio desechando las ideas románticas sobre la creación literaria del escritor individualista. Siguiendo la senda trazada por $\mathrm{Ch}$. Baudelaire, Stendhal (1783-1847), etc. en el s. XIX, y por T. S. Eliot, J.L. Borges, etc. en el s. $\mathrm{XX}, \mathrm{B}$. Atxaga muestra su disconformidad sobre estas ideas románticas. Consciente del adagio latino "nihil novum sub sole" ( no hay nada nuevo bajo el sol) intenta mostrar que la creación literaria "ex nihilo" (comenzando de cero) no es posible. La imaginación (tan encumbrada por los románticos) halla siempre un contrapeso en la memoria (por la que recordamos el pasado) y la aportación de una larga lista de escritores que influyen en las generaciones siguientes. Todo el pasado literario universal seguirá estando a disposición de los escritores contemporáneos $\mathrm{y}$, en consecuencia, el plagio resulta inevitable, necesario y útil para cualquier autor que escribe en lengua vasca. El mencionado cuento está presentado en forma de una gran alegoría compuesta de metáforas consecutivas : la isla (euskara) ; el navío negro y los distintos grupos que navegan en él ; el plato de higos de la sabiduría ; el buque Grand Saint Antoine (portador de la peste a Marsella); la selva, la pendiente y las dos cimas; Getsemaní (lugar del beso dado por el traidor Judas a Jesús), etc.

Estando el protagonista - narrador en Obaba, tiene un sueño en el que se ve a sí mismo en medio de una selva cercana a una pendiente con dos cimas. Inicia la ascensión a una de ellas dejando atrás las tinieblas de la selva y se topa con un desconocido a quien no reconoce si es sombra o un ser humano. El enigmático personaje confiesa que está muerto : "Ez nauzu gizon bat, baiña hala izan nintzen" (no soy hombre pero lo fui, p. 330) y que su nombre es Pedro Daguerre Azpilicueta, "Axular". El narrador canta las excelencias del gran maestro y escritor navarro : "zu zara nire maisua eta nire egilerik maitatuena" (p. 330). Ambos ascienden a una segunda cima desde la cual el discípulo constata que se halla en una diminuta isla perdida en medio del mar : "Zein labur eta eskas den!" (p. 331). Se entabla un diálogo entre el Maestro y el alumno sobre el euskara. El autor inserta (con alguna pequeña variante) un texto de "Axular" a favor de la lengua vasca, tomado de la introducción de su famoso libro Gero (Después, 1963).

"Baldin egin baliz euskaraz hanbat liburu, nola egin baita latinez, frantzeses, edo bertze erdaraz eta hizkuntzaz, hek bezain aberats eta konplitu izanen zen euskara ere, eta 
baldin hala ezpada, euskaldunek berèk dute falta eta ez euskarak." ${ }^{32}$

(Si se hubieran hecho en euskara tantos libros como se han hecho en latín, francés o en otras lenguas extranjeras, también el euskara sería tan rico y perfecto como ellas, y si esto no es así, los mismos vascos son los que tienen la culpa de ello, y no el euskara.)

En el mencionado navío negro, semejante al Grand Saint Antoine, se distinguen cinco grupos de personas, situados en otras tantas zonas distintas. Con una ironía mordaz, el narrador va criticando a estas personas, siendo esta crítica especialmente acerada cuando se refiere a los del cuarto grupo : "mastan igota daudenak" (los encaramados al mástil, p. 333). Los compara con los sapos hinchados, y los trata de arrogantes, ruines e inmundos por atacar y mofarse de una lengua débil, el euskara. Además de despreciarla, buscan alguna laguna cercana a la Corte, donde poder vivir tranquilamente ; son los partidarios de la marginalización del vascuence en la sociedad actual.

Una vez descendidos al valle, se reanuda al diálogo pero esta vez, sobre el tema del plagio. Ambos se manifiestan partidarios del plagio por sus grandes ventajas, a condición de que se efectúe con destreza. Por ello, el Maestro da unos consejos al discípulo mostrándole la necesidad de crear un método que respete tres requisitos. "Axular" le pide que vuelva al mundo a preparar ese método, pero, antes le ofrece un plato lleno de higos de sabiduría. En un momento dado del sueño, "Axular" desaparece en una nube, y el protagonista - narrador se despierta volviendo a la dura realidad de la vida cotidiana, desvaneciéndose de esta forma la frontera entre el sueño y la realidad. No le resulta fácil cumplir la promesa hecha al Doctor Angélico de Euskal Herria pero acepta el compromiso gracias a la sabiduría producida por esos higos especiales y al comprobar que el plato de higos que halla en su habitación de Obaba es el mismo que "Axular" le ofreció en el sueño. Rápidamente, comienza a preparar el método de plagiar bien respetando tres normas fundamentales (pp. 337-339), y buscando otros tantos argumentos para que un plagiario pueda defenderse en caso de ser acusado como tal (p. 340). El autor, pasa de la teoría a la práctica, y al final de este cuento menciona el título del siguiente, propuesto como ejemplo que reúne las tres condiciones exigidas para lograr un buen plagio.

En el cuento "Pitzadura bat elur izoztuan" (Una grieta en la nieve helada), B. Atxaga cuenta el ajuste de cuentas entre dos alpinistas suizos por razones sentimentales. En este suceso ocurrido en las montañas del Nepal, el alpinista Mathias Reimz, salva la vida de su antiguo amigo, Philippe Auguste Bloy, que yace herido en una grieta helada ; no le mueve a ello ninguna razón humanitaria. Prepara un ardid en la nieve helada, y cuando el herido consigue salir del precipicio, empuja a su rival al abismo por el placer de mostrarle antes de morir, lo mucho que le

${ }^{32}$ Pedro Axular. Gero, Arantzazu-Oñad, Jakin, 1976 : 16-17. 
odiaba por haberle engañado acostándose repetidas veces con su esposa Vera : "Zenbat gorrotatzen hauten esan nahi nian", (p. 350). En este cuento se observa también la presencia constante del dolor humano junto a la autonomía y a la aventura de la escritura.

Como colofón de estas reflexiones sobre Obabakoak presentamos el finai de esta novela que va unido temáticamente con el principio de la tercera parte en el cuento "Aspaldi, artean gazte eta berde ginela", (p. 199). En ambos pasajes se narra la enfermedad mental de Albino María causada por la introducción de un lagarto en su conducto auditivo : "belarritik sartu eta buruko muinak jaten dituztela?", $(\text { p. } 362)^{33}$

El narrador, que asiste a las veladas literarias de su tío indiano en su casa de Obaba, correrá al final la misma suerte que Albino María. Este narrador, tras recorrer distintos continentes y parajes del mundo en busca de la última palabra (Obaba, Hamburgo, Bagdad, Villamediana, Montevideo, Amazonia, Dublín, Nepal, Suiza, etc.) concluirá que es imposible hallarla "hitzak ez zeukala niregana etortzeko asmorik. [...] Azken hitza ez zen inondik azaltzen", (p. 398).

\section{Behi euskaldun baten memoriak (1991)}

Las novelas de B. Atxaga están repletas, en general, de personajes tristes y problemáticos. Si nos fijamos en las tres analizadas hasta ahora, observaremos que los temas del homicidio, suicidio, discriminación, violencia, soledad, aislamiento, locura, etc. son frecuentes en ellas. Podríamos afirmar otro tanto de Gizona bere bakardadean y Zeru horiek. En cambio, la novela Behi euskaldun baten memoriak (Memorias de una vaca vasca) es una excepción en medio de esa tónica general, por el carácter alegre y jocoso de algunas situaciones y personajes, a pesar del tema postbélico que conlleva, y de la soledad, angustia y monotonía que condicionan la vida de los protagonistas. Por otra parte, aunque su éxito de ventas fue pobre al principio en el País Vasco, finalmente ha sido muy satisfactorio, pues ha alcanzado veinte ediciones en euskara convirtiéndose así en la novela vasca que más reediciones ha logrado ; asimismo, a finales de 1995 ocupó los primeros puestos en el ranking de libros más vendidos en Alemania. Esta obra podría estar catalogada dentro de la literatura infantil por su carácter fabulístico, corriendo así el riesgo de no valorar la rica semántica que subyace en ella. Es, sin duda alguna, un libro escrito más para adultos que para niños y adolescentes. Por ello, pensamos que cualquier lector adulto interesado en la literatura y mínimamente capacitado, disfrutará de muchos momentos de goce y alegría que no hallará en el resto de las novelas de B. Atxaga, por tratarse de su novela más divertida y una de las mejor logradas.

Podríamos adelantar desde el principio algunas de las notas que caracterizan a esta obra al describirla como festiva, original, política, humorística y amarga,

${ }^{33}$ B. Atxaga. Obabakoak : 362. Sobre este particular, recomendamos al lector el artículo del autor titulado "El lugar extraordinario", La Modificación, Madrid, nº 9-10 (Jul-Ag., 1999) : 18-25. 
sencilla y profunda, ingenua e irónica, singular y extraña, histórica y autobiográfica, simbólica y surrealista, llena de suspense y de intriga, repleta de acción, diálogo y monólogo interior. Además, tres de las palabras que componen su título, describen a grandes rasgos el contenido de este libro. Como eje central de la novela aparece una vaca ; pero como reza la canción popular, "no es una vaca cualquiera" pues, además de dar patadas a los lobos, sabe pensar, escuchar la voz de su conciencia, y escribir sus memorias impulsada por una fuerza interior. Es, además, una vaca vasca, pues se expresa en euskara y es capaz de comprender el dialecto de Zuberoa (el más difícil de los dialectos vascos, "[...] hizkera deabru horretan [...]" p. 35), en el que se expresa su amiga, la monjita de Altzürükü, que le acogerá en su convento. Finalmente, este personaje singular escribe sus memorias comprendidas entre 1940 y 1990. (?)

\section{Argumento}

En el umbral de la novela hallamos la canción popular francesa : "Au clair de la lune [...]", (p. 13). Ello podría interpretarse como un avance del carácter intertextual y dialectal que embellecerá muchas páginas de la obra con citas francesas y largos pasajes escritos en el dialecto de Zuberoa, dentro del vascuence unificado en el que aparece la novela. La vaca Mo (sonido onomatopéyico de mugido) nace en un caserío muy especial, Balantzategi, en el que no hay ningún perro, ni gallinas, ni ovejas y sirve de almacén de avituallamiento de los maquis republicanos escondidos entre las montañas : "Horixe da Balantzategik orain egiten duen zerbitzua, almazena bezalako zerbait da mendikoentzat", (p. 111). Estos maquis, tras ser derrotados en la Guerra Civil Española (1936-1939), luchan todavía contra las fuerzas de un general en un rincón, sin ubicación precisa, del País Vasco.

"Hogeitamaseian hasi zen gerra ez da oraindik bukatu. Gure haran honetan behintzat ez. Menditik Balantzategira izkutuan jaisten diren horiek ez dute etsi nahi, eta Espainiako jeneralaren aurka ari dira. ${ }^{134}$

(La guerra que empezó en el treinta y seis, aún no se ha acabado. Al menos no en nuestro valle. Los que bajan secretamente del monte a Balantzategi no quieren rendirse y siguen luchando contra el General de España.)

Mo convive con otras once vacas (siete negras como ella y cinco rojas) durante los dos primeros años de su existencia (1940-1941) en ese caserío. Este período de tiempo ocupa siete de los nueve capítulos de la novela y aparece descrito con muchos detalles, desde la lucha encarnizada de Mo contra dieciséis lobos en medio de una noche de rayos y truenos: "[...] txismista eta trumoi gau batez [...]", (p. 175). Fue precisamente en esa noche, cuando Mo prometió escribir en un futuro sus memorias, como se lo recordará más tarde su voz interior : "[...] neronek esango

${ }^{34}$ B. Atxaga. Behi euskaldun baten memoriak, (2. ed), Iruñea, Pamiela, 1991: 109. 
dizut otsoengandik aldegin egunean agindutakoa. Esan zenuen : egun batean nire memoriak idatzi eta gaurkoa kontatuko dut." (p. 29). Tras medio siglo de existencia y hallándose ya en el ocaso de su vida (como se puede comprobar en el último capítulo) Mo se decide a cumplir aquella promesa siguiendo el dictamen de su voz interior: "Barrukoak idazteko agintzen dit.", (p. 179). Son muchos los recuerdos, contratiempos y pormenores que debe consignar : sus dos años de niñez en Balantzategi en cuyos alrededores aparecen los restos de un avión estrellado y tres cruces que recuerdan a otras tantas personas fusiladas por los vencedores(una de ellas perteneciente al marido de Genoveva, la dueña de Balantzategi.) ; las malas relaciones con los enemigos del caserío, D. Gregorio, alias "Antiaju Berde" y sus sicarios : "Balantzategiko etsaiak! Antiaju berde eta bere laguntzaileak!", (p. 101.) ; la compañía de su mejor amiga "La Vache qui Rit" y la antipatía hacia las vacas rojas especialmente "Bidani" ; las trampas urdidas por Genoveva (propietaria del caserío) y por su fiel criado Usandizaga, "Bizkar Oker" (Encorvado) a los treinta guardias enviados por el General a colaborar con "Antiaju Berde" para impedir el avituallamiento de los maquis ; la lucha continua de Mo para no convertirse en una vaca corriente : "Baina ez nuen nolanahiko behia izan nahi [...]",( p.88) ; la venta de Mo y de "La Vache qui Rit" efectuada por los dos hermanos "Hortzaundi" (Dentudos) a unos jóvenes que preparan una fiesta taurina : "[...] ganadu paregabea festa jartzeko.", (p. 141) ; la huida al monte junto a "La Vache qui Rit", con la consiguiente soledad y aburrimiento ; la decisión de su "copine" de metamorfosearse en jabalí ; el encuentro inesperado, irreal y surrealista de Mo con Pauline Bernardette quien la toma como dote para ingresar en un convento de religiosas ; la vejez de Mo : "Ez dut ezer, Soeur. Bakarrik zahartu egin naizela", (p. 177), etc.

\section{Estructura}

Esta novela se compone de nueve capítulos regulares; siete de ellos contienen entre 20 y 25 páginas; el segundo capítulo tiene 14 y el capítulo final consta sólo de 6 páginas. La historia de la vaca Mo está descrita con muchos detalles a través de los capítulos 1-8; el noveno y último capítulo está dedicado a la redacción de las memorias de Mo en cuya corrección pasará diez años : "Hamar ürte haik korrejitzen, orraztzen eta apaintzen iragan ondoan [...].", (p.179). La mayor parte de la novela aparece en forma de narración, pero abundan también los diálogos que aligeran el ritmo de aquélla. El Setatsu (Testarudo) o voz interior de Mo, merece una atención especial. Una vez más, el autor se vale de este recurso literario (usado ya en Bi anai, y como veremos más tarde, en Gizona bere bakardadean) para conformar una novela original e interesante. El apelativo Setatsu (repetido en una ocasión hasta seis veces consecutivas, es comparado con un piojo por su persistencia a la hora de aconsejar a Mo : "Zorria bera baino setatsuagoa!", (p. 16). En general, se muestra como muy buena amiga de Mo, aunque a veces disienten a la hora de tomar una decisión: "[...] Setatsua ez zegoen amore emateko prest.", (p. 22). En ocasiones, hasta le introduce en el conocimiento de la astronomía (Venus, Andrómeda, Orión, Sirio, etc. (p. 93-94). Se desconoce la naturaleza de esa voz interior que ni la misma Mo es capaz de definirla y la compara con algo espiritual o metafisico ; sólo le consta que la lleva dentro."Deituko nion Aingeru Goardako, 
deituko nion Izpiritu, Mintzo, Ahots edo nahi dena, baina izen batekin nola bestearekin, hura beti nire barruan [...]", (p. 15). (Le llamara Ángel de la Guarda, Espíritu, Habla, Voz, o lo que fuere, pero tanto con un nombre como con otro, permanecía siempre dentro de mí.)

El valor simbólico de algunos nombres, conceptos y personas embellecen también esta novela tan singular: Pauline Bernardette, nacida en un pueblo cercano a Lurdes, evoca la imagen de la vidente Bernardette Soubirous ; "Antiaju Berde" con su forma extraña de hablar ("Karral, Karral, Karral") simboliza la fuerza extranjera y opresora en el Pais Vasco ; el General (escrito con letra mayúscula) representa a F. Franco ; los dos hermanos "dentudos" son el prototipo del sicario, etc. Otro tanto se podría afirmar del desierto (símbolo de soledad y marginación) tan del gusto del escritor de Asteasu. La expresión "Sekretuen Gurpil Haundia" (La Gran Rueda de los Secretos), tan repetida en la última parte de la novela (pp. 114, $117,120,121,135,176)$ se asemeja a la rueda del tiempo que gira incesantemente desvelando paulatinamente el contenido de los acontecimientos inescrutables. Las letras Alfa y Omega (primera y última del alfabeto griego) podrían representar el proceso evolutivo de los seres animados (pp. 107-108). La presencia de dos personajes renombrados en la cultura vasca : el bertsolari guipuzcoano "Uztapide" y el dramaturgo labortano P. Larzabal (combatientes en la Guerra Civil Española, y en la II Guerra Mundial, 1939-1945) completan el cuadro simbólico de esta obra original.

\section{Personajes}

"Mo". Nace hacia 1940 en Balantzategi : "Mundura 1940 garren urte aldera etorri nintzen [...].", (p. 34). Desde muy joven duda sobre su propia identidad ; no se conoce bien a sí misma y se pregunta quién es : "Zer ote naiz?- galdetu nion neure buruari.", (p. 37). Apoya a Genoveva y a los maquis, mostrando una rebeldía innata contra vencedores en la Guerra Civil. Detesta ser una vaca corriente y preferiría convertirse en caballo o simplemente en gato, pero finalmente decide ser "una auténtica vaca". Mo es el personaje más problemático de la novela, además de convertirse en narrador y protagonista. Tras pasar cuatro años en compañía de "La Vache qui Rit", ésta la abandona en el monte, y se ve obligada a bajar a un pueblo de Zuberoa donde se topa casualmente con Pauline Bernardette a quien la defiende, hiriendo a un joven que la ha ofendido por su pequeña estatura : "[...] aurreratu nituen adarrak eta besoa hautsi nion bi lekutatik", (p. 76).

"La Vache qui Rit". Es la mejor amiga de Mo durante cuatro años, en opinión de ésta : "J'avais une copine", (p. 156) ; ambas dialogan constantemente. Es muy luchadora y le desagradan mucho las vacas "makalak", esto es, aquellas que se limitan a pastar en las verdes praderas del caserío. No quiere seguir siendo una vaca corriente, pues no hay en el mundo cosa peor que esto : "Ez dut behi izan nahi. Mundu honetan ez dago behi makala baino gauza makalagorik!", (p. 161). Le gustaría, en cambio, convertirse en jabalí.

Soeur Pauline Bernardette. Este personaje no aparece directamente implicado en los acontecimientos de Balantzategi ni en los primeros capítulos aunque se le 
menciona a menudo usando la técnica retrospectiva de anticipación del flash back, que rompe el orden cronológico regular de los acontecimientos pasados. Así, por ejemplo, se afirma : "Baina, utzi oraingoz Pauline Bernardetteren kontuak eta jarrai dezadan nire jaiotegunean gertatutakoarekin.", (p. 41). (Pero dejemos por ahora las historias de Pauline Bernardette y sigamos con lo ocurrido el día de mi nacimiento). A medida que avanza la novela, su papel va alcanzando gran importancia por ia influencia que ejerce sobre la vaca Mo. Pauline se ve obligada también a pasar su propio desierto existencial al verse ante el dilema de entrar de religiosa en un convento o casarse, tal como desean sus padres: "Pauline Bernardetteren desertua, beraz, ezkontza deitzen zen [...].", (p. 88). El accidentado encuentro de Pauline con Mo (se cae de una ventana sobre la vaca) sirve para que, más tarde ésta pueda vivir de por vida en el convento donde ingresará la novicia. Ella la hará feliz prodigándole toda clase de cuidados pero, sobre todo, por la bondad con que la trata : "[...] nire mojatxoak zera ematen du, bihotz baten partez, hamar bihotz ttiki dituela [...].", (p. 67). (Mi monjita aparenta tener diez pequeños corazones en lugar de uno solo.)

Entre los personajes secundarios destacan Genoveva que será arrestada y su anciano criado Usandizaga, "Bizkar Oker", que morirá en un tiroteo entablado contra las fuerzas de "Antiaju Berde", el peor enemigo que Mo conoció en toda su vida : "[...] pertsonarik etsaiena[...].", (p. 44). Finalmente, están los "Hortzaundiak" (Dentudos), dos hermanos gemelos, sicarios de "Antiaju Berde", que al final serán recompensados por su colaboración.

\section{Coordenadas espacio-temporales}

La acción de esta novela se desarrolla en el País Vasco; en un lugar indeterminado en torno al caserío Balantzategi, y en la provincia de Zuberoa, dentro de un convento. Gran parte de la obra gira en torno a este caserío y a sus alrededores. Una inesperada descripción del mismo situará al lector en este lugar extraño y conflictivo.

"Balantzategin behiok behi gara, eta belarra belar. Baina gainerako gauza guztiak ez dira ematen dutena. Hasteko ez da nekazari etxea. Hala dirudi, baina ez da. Ikusi duzu atarian zakurrik ez daukatela eta behiok ezer ez dugula egiten. Baina, horretaz gain, ohar zaitez, oilorik ez daukate, ardirik ez daukate, segan ez dakite...hori da haundiena, ez Genoveva eta ez Bizkar Okerrek ez dakitela segan". 35

(En Balantzategi las vacas somos verdaderas vacas, y la hierba es auténtica hierba. Pero las demás cosas no son lo que aparentan. Para empezar no es una casa de labranza. Lo parece pero no lo es. Ya has visto que no tienen perro delante de la puerta $y$ que las vacas no

${ }^{35}$ Ibid. : 111 . 
hacemos nada. Pero además, ten en cuenta que no tienen gallinas, ni ovejas, ni ningún otro animal doméstico, ni saben segar...lo más gordo del caso es que no saben segar ni Genoveva ni el "Encorvado.")

Junto a nombres de la geografia vasca de la provincia de Zuberoa (Altzürükü, Urdinarbe, Kakoeta) aparecen otros lugares del universo (Grecia, Troya, Esparta, etc.). A la hora de narrar la importancia de la vaca en algunas partes de Asia, se mencionan los países de Pakistán y de la India.

En cuanto a la coordenada temporal conocemos la fecha del nacimiento de Mo, 1940, en torno al cual arranca la novela : "Eta mendea bera ere gaztea zen orduan, 1940an geunden eta ; orain, berriz, mendea bukatzen ari da" ( $y$ hasta el mismo siglo era joven entonces, pues estábamos en 1940 ; ahora, en cambio, el siglo se está acabando). A diferencia de la mayoría de las novelas de B. Atxaga, ésta no ofrece gran dificultad en este terreno, aunque a veces se limita a dar ideas muy generales, por ejemplo : "[...] Denboraren Gurpila gozo gozo jiratzen hasi zen : eta udazkenari negua jarraitu zitzaion, eta neguari udaberria, eta udaberriari, berriro ere, uda.", (p. 157), [...]. (La Rueda del Tiempo comenzó a girar lentamente y al otoño le siguió el invierno, $\mathrm{y}$ al invierno la primavera, y a la primavera, de nuevo, el verano...). En cambio, algunas otras citas temporales son más precisas y aportan más luz a la hora de limitar el transcurso de la novela. Así, por ejemplo, al comentar Mo su última temporada pasada en compañía de "La Vache qui Rit", afirma : " Gure mendiko bigarren urtean [...].", (p. 158), (En el segundo año pasado en el monte). Con estos y algunos otros datos podemos completar a grandes rasgos la biografía de Mo (1940-199 (¿?)), de los que los dos primeros años los pasó en Balantzategi (1940-1941) ; otros dos en la montaña en compañía de su "copine" (1942-1943), y el resto de su vida en el convento con Pauline Bernardette (1944$1990(¿ ?))$, de los que vivirá una década corrigiendo sus memorias.

\section{Estilo}

La influencia de la literatura oral es también notoria en esta novela. Aparte de la mención del bertsolari "Uztapide", señalada anteriormente, los numerosos refranes (17); los bellos cantos populares de Zuberoa, que aparecen especialmente en el capítulo séptimo ; el parangón que el autor establece entre la canción "Agur Euskal Erriari" del bardo J.M. Iparragirre y una de las frases del texto, son algunas de las pruebas que confirman esa influencia popular y oral de la literatura vasca en esta obra de B. Atxaga.

"Mundu honetan belar ederrak badira baina bihotzak dio zoaz Balantzategira". (p. 36)

(Hay hermosos pastos en este mundo pero mi corazón me dice vete a Balantzategi.) 
"[...] Erri-alde guzietan

toki onak ba-dira, baiña biotzak dio :

"Zoaz Euskal - errira." 36

(En todas partes hay hermosos lugares, pero mi corazón me dice : "Vete al País Vasco".)

Entre las figuras retóricas más frecuentes resaltaría la repetición "kontra" de la página 73, que aparece repetida seis veces. " Laguna defendatu egin behar da beti otsoen kontra [...], (Hay que defender siempre al amigo contra los lobos). Esta frase nos evoca también la famosa poesía "Nire aitaren etxea" (La casa de mi padre) de G: Aresti, que comienza de esta forma "Nire aitaren etxea defendituko dut./Otsoen kontra $[. ..]{ }^{37}$ (Defenderé la casa de mi padre contra los lobos...). Mientras el poeta vizcaíno emplea cuatro veces la preposición "kontra", el escritor de Asteasu la repite seis veces.

En el aspecto lingüístico, sólo nos queda resaltar lo afirmado anteriormente sobre la combinación que el autor logra entre el vascuence unificado y el dialecto de Zuberoa, logrando siempre un vascuence llano, cotidiano y coloquial, pero muy rico, lleno de colorido, musicalidad y de diferente grafia que se pueden apreciar, por ejemplo en este pasaje.

- "Altzürükün bizi nintzelarik - kontatu zidan egun batean -, irus eta kuntet bizi nindüzün. Egün osoa bortüan nihaur bakarrik iragaiten nizün, kabalen begiratzen, eta horrekin eta Jinko jaunari egin otoiekin aski nizün. Hartan gizendü eta edjertü nindüzün, izigarri neskatila polita nindüzün. Eta erran zitadazün aitak : "Esposatü beharko düzü, joan zite iganteetako sonüra". Nik erraiten neiozün :"Ez aita, untsa nüzü bortüan kabaleekilan". Eta aitak, oraino : "Hebendik aintzina ez zira kabaleekilan bortüra joanen. Behar düzü Madmoiselle bilakatü, eta sonüra joan eta ontsa esposatü." ${ }^{38}$

(Cuando yo vivía en Altzürükü - me contó un día vivía feliz y contenta. Pasaba el día entero sola en la montaña, cuidando el ganado, y con eso y con las plegarias que le dirigía a Dios, tenía suficiente. Me fui creciendo y embelleciendo hasta llegar a ser una joven muy bonita. Y entonces mi padre me dijo: " Tendrás que casarte ; para ello debes ir al baile los domingos. Yo le contesté : "No padre, estoy bien cuidando el ganado en el monte. Y mi padre continuó diciendo : "De ahora en

\footnotetext{
${ }^{36}$ Luis de Castresana. Vida y obra de Iparraguirre, Bilbao, La Gran Enciclopedia Vasca, $1997: 244$.

${ }^{37}$ Gabriel Aresti. Poemak (I), Donostia, Kriselu, 1976: 482.

${ }^{38}$ B. Atxaga. Behi euskaldun baten memoriak (2 ${ }^{\mathrm{a}}$ Ed.), Iruñea, Pamiela, 1991 : 86.
} 
adelante no irás a la montaña sino al baile porque debes convertirte en una señorita casadera.)

\section{Gizona bere bakardadean (1993)}

Esta novela muestra un cambio profundo en la novelística de Bernardo Atxaga y supone un nuevo desafio por ser su primera novela larga en el sentido estricto de la palabra. Este nuevo giro es debido al realismo literario tan escaso hasta 1993 en su narrativa ligada preferentemente a la fabulación mítica y los espacios imaginarios. Carlos, como varios de los personajes principales es vasco, y se describen situaciones basadas en hechos reales que ocurrieron en las primeras décadas de E.T.A. Aunque, en ocasiones, se cita en este libro el pueblo de Obaba como lugar de nacimiento del protagonista principal (Carlos) y de su hermano (Kropotki), esta obra dista mucho de Obabakoak. En cuanto a la aceptación de la novela conviene recordar que fue galardonada como ganadora del Premio de la Crítica concedido en 1993 por la Asociación Española de Críticos literarios, y finalista al Premio Nacional de Narrativa en el mismo año. Asimismo, tuvo una acogida muy favorable en Europa, especialmente en Alemania, Francia e Italia. Cualquier lector, mínimamente aficionado a la literatura, se sentirá como atrapado entre las redes de esta obra cuidadosamente elaborada ; llena de suspense especialmente al final de ella; tensa y policíaca, pero, también psicológica (sobre todo en el análisis de la soledad en la que vive Carlos); repleta de extensos diálogos y de monólogos interiores; realizada por múltiples e interesantes personajes entre los que destaca Carlos, abocado al fracaso, a la soledad, y a la conciencia de culpabilidad que le conducirán fatalmente al suicidio.

\section{Argumento}

El título del libro Gizona bere bakardadean (El hombre solo, o El hombre en su soledad) refleja el núcleo del tema central. El protagonista principal, a pesar de aparecer, en ocasiones, como un héroe, vive sumido en una profunda crisis : soledad familiar (sólo le queda un hermano a quien ha ingresado en un hospital psiquiátrico) : soledad de un antiguo miembro de E.T.A., desilusionado con la trayectoria de este grupo ; soledad y falta de estabilidad emocional en sus relaciones amorosas con varias mujeres ; soledad psicológica producida por una profunda sensación de culpabilidad recordada repetidas veces por varias voces internas de su conciencia, viviendo fuera del País Vasco : "[...] familiarik gabe ; zinezko lagunik gabe, zinezko maitalerik gabe. Ba ote zen deserria baino gauza okerragorik?", ( p. 200). Esta sensación de soledad, constante a lo largo de toda la obra, queda patente desde el principio pues comienza con un epígrafe tomado del Eclesiastés (IV, 10) : "Errukarria bakarra jausten ba'da : ez dauko jaso dagianik" (; Ay del que cae solo!, que no tiene quien lo levante.)

La novela está dividida en diez partes (a modo de capítulos sin numerar) que suman 349 páginas en las que se narran los problemas que se crean al ocultar durante casi dos semanas a dos miembros activos de E.T.A. a quienes se pretende 
liberar del estrecho cerco montado por la policía. La obra arranca con la imagen de un mar helado por cuyas grietas desaparecen las gélidas aguas, y finaliza con una gran charca ( La Banyera de Samsó) por cuyo sumidero desaparecerá también Carlos, ahogándose voluntariamente en su sima. El primer párrafo de la novela revela resumidamente el contenido y la estructura de la misma al presentar al protagonista Carlos, el lugar donde se desarrolla la trama, y las circustancias temporales concretas en las que ocurren los hechos.

"Carlos esaten zioten gizonak bazekien Itxaso izoztua amets-irudi bat besterik ez zela, eta bazekien ere zeren halaxe adierazten baitzion zakarki bere kontzientziaren ahotsetako batek -, [...] hoteleko behe saloira jaitsi [...] astelehen hartan, 1982ko Ekainak 28 $[\ldots]^{\prime \prime 39}$

(El hombre al que todos llamaban Carlos sabía que el mar helado que contemplaba era solamente la imagen de un sueño [...] y también sabía (porque se lo recordaba bruscamente una de las voces de su conciencia), [...] y bajar al salón de la planta baja del hotel [...], en aquel lunes, 28 de junio de 1982 [...].)

Carlos es un personaje condicionado por el pasado. Tras pasar cinco años en la cárcel en compañía de Ugarte y Guiomar (miembros del mismo comando) compran un pequeño hotel en las cercanías de Barcelona con el dinero obtenido en dos atracos. Sin consultar con sus dos amigos, se compromete a ocultar durante una semana en el hotel a dos militantes de E.T.A. (Jon y Jone) que se han visto obligados a huir de Bilbao tras cometer un atentado sangriento. Se da la circunstancia de que la selección del fútbol de Polonia se halla concentrada en ese mismo hotel con ocasión de los Campeonatos Mundiales de Fútbol de 1982. Unos treinta policías merodean el lugar sospechando que los dos etarras huidos se hallan escondidos en ese hotel. La historia de la trama se complica hasta el desenlace final en el que mueren trágicamente Carlos y el niño Pascal, tras conseguir liberar a los militantes etarras.

\section{Estructura}

B. Atxaga emplea técnicas literarias complejas como la fragmentación de las coordenadas espacio-temporales, el flash-back, el suspense, la variedad de las voces interiores de la conciencia de Carlos, etc. La novela está contada en tercera persona por un narrador omnisciente ; está, además, narrada desde el interior de Carlos al que se va analizando psicológicamente desde el principio hasta el final de la obra. Existe además un narrador interior que cuenta los hechos en primera persona. Por otra parte, el ritmo se aviva y la tensión narrativa crece al final de la novela, a medida que el cerco policial se va estrechando en torno al hotel en busca de los

${ }^{39}$ B. Atxaga. Gizona bere bakardadean, Iruñea, Pamiela, $1993: 9$. 
miembros de E.T.A. Es de resaltar el uso de algunas técnicas que el autor empleó anteriormente en la novela fantástica, v.g. : las voces internas en la obra Bi Anai. En Gizona bere bakardadean aparecen varias voces distintas que corresponden a otros tantos estados diferentes de la conciencia de Carlos, entre las que sobresalen especialmente tres : la de Sabino (antiguo jefe del comando etarra en el que militó Carlos) ; la de su hermano mayor, Kropotki, (recluido en un sanatorio psiquiátrico) ; y una tercera voz que el autor la denomina como "arratoi" (rata). La voz de Sabino (la más frecuente) puede ser considerada como la positiva pues aconseja a Carlos de forma favorable. En el lado contrario, hallamos la voz de la "rata", tentadora y recriminatoria, aunque algunas de sus críticas sean válidas. Finalmente, está la voz de Kropotki, que refleja la conciencia sin esperanza e ilusión. Son, en general, recuerdos que atormentan y culpan a Carlos que se ve acechado continuamente desde el principio hasta el final de la novela. Como se ve, son voces diversas, a veces contrarias, que se van multiplicando $\sin$ orden y que van aprobando, asesorando, criticando y condenando las actuaciones pasadas y presentes de Carlos. En la mayoría de los casos, estas voces están diseminadas individualmente a lo largo de toda la obra, pero, en ocasiones, aparecen simultaneadas una detrás de otra, como en este pasaje en el que se detectan excepcionalmente cuatro voces diferentes.

"Jarraitu hola, jarraitu gaizki-ulertua gizentzen [...] entzun zuen. "Ez diat uste beste astazakil horrena kezkatzekoa denik, benetan", entzun zuen jarraian" [...] Dena dela kezkatzekoa da", esan zuen hirugarren ahotsak, Kropotkirenak. [...]" Gu Ezpainarekin gaude", esan zuen laugarrenak $[\ldots] " .40$

(Sigue así, sigue permitiendo que el malentendido se extienda $[\ldots]$ oyó $\left(\mathrm{l}^{\mathrm{a}}\right.$ voz $)$. "En verdad, no creo que lo dicho por ese bruto sea para preocuparse", oyó a continuación [...], ( $2^{\mathrm{a}}$ voz). Así y todo, es preocupante dijo la tercera voz, la de Kropotki [...] "Nosotros estamos con Ezpainas, dijo la cuarta voz $[\ldots]$.)

Además de la multiplicidad de voces, el autor se vale de otros recursos literarios como el monólogo interior tan frecuente del protagonista principal, presentado desde el interior del propio narrador. Igualmente el uso constante del flash-back en el que la memoria se retrotrae evocando recuerdos del pasado: los escritos de la revolucionaria polaca Rosa Luxemburgo ; las referencias al príncipe anarquista ruso P.A. Kropotkin ; las alusiones a las cartas escritas por "Kropotki" a su hermano Carlos detenido en la cárcel, etc. La superposición de planos es también frecuente en esta obra : el mar helado connota la muerte del protagonista en La Banyera ; las relaciones entre los pendientes de esmeralda deseados por Danuta con las conchas prehistóricas "Vassa Reticulata" o "Littorina obtusata" repetidas con frecuencia, etc. son algunos de los recursos que usa el autor.

${ }^{40}$ Ibid. : 300 . 


\section{Personajes}

Este apartado es uno de los más interesantes de la obra por el número y la variedad de los personajes. El autor los presenta desde el comienzo de la novela facilitando, de esta foma, al lector la comprensión de ella. Con el mismo objetivo en la mente, los podriamos clasificar por el momento en principales y secundarios. Entre los primeros incluiríamos a Carlos, con sus dos compañeros (Ugarte y Guiomar) y a la intérprete polaca Danuta. Entre todos ellos destaca, con mucho, el análisis intemo del protagonista principal, Carlos.

Carlos. Aparece como el personaje central de la novela ; el que da comienzo y fin a la obra. Es una persona cercana a los cuarenta años y marcada por su vida de militancia etarra : secuestros, atentados sangrientos, muerte violenta de varios amigos, internamiento de su hermano Kropotki en un psiquiátrico, etc. Se conocen pocos detalles físicos de su persona, aparte de su calvicie por la que es conocido como Yul Brinner ; ni siquiera el nombre Carlos es su nombre de pila sino un seudónimo por el que se le conoce desde la militancia en el comando dirigido por Sabino. Nació en Obaba, y al final de la adolescencia fue captado por E.T.A. Toma parte activa en el secuestro de un industrial al que (después de tenerle veinte días en un sótano) lo ejecuta, siguiendo las normas dictadas por la dirección de E.T.A. Es detenido y encarcelado durante cinco años pero en 1977, es liberado gracias a la amnistía general en compañía de sus dos amigos, Ugarte y Guiomar. Los años vividos en la clandestinidad en el reino de "Don Beldur" (Don Miedo) le dejarán secuelas imborrables de por vida. En general, es esquivo con la mayoría de la gente, y se refugia en la naturaleza (La Banyera y el entorno del hotel), y en la compañía de sus dos fieles amigos, los perros Greta y Belle. Ni el cariño hacia Pascal, ni la amistad con Ugarte y Guiomar, ni las relaciones amorosas y pasajeras con varias mujeres llenarán el abismo de soledad en el que vive. Se le ve decepcionado por el desarrollo de la lucha armada a la que considera absurda, según la confesión hecha a Jone : "Nik uste dut oraingo borroka absurdoa dela - erantzun zion Carlosek lehorki.", (p. 40). Como hemos visto anteriormente, tras su liberación organiza dos atracos (en compañía de Ugarte y Guiomar) con cuyo botín compran el hotel donde viven. Para blanquear el dinero robado se vale de un ardid cuyas consecuencias sufrirá durante toda la vida. Declara demente e insolvente a su hermano mayor para apropiarse de los bienes familiares que ambos poseen en Obaba. Más tarde, sin contar con los otros dos propietarios del hotel, acepta (como miembro retirado) e] compromiso pedido por la organización etarra, de ocultar durante una semana a dos miembros de ella : "Bera aldi bateko laguntzailea besterik ez zen, mesede bat egiten ari zen militante erretiratu bat", (p. 30).

Para huir de la tensión en la que vive, se refugia a menudo en el escondite de la panadería (donde da cobijo a los dos militantes etarras) en cuya puerta está colgada la carta-poema que su hermano mayor le escribió a la cárcel. Es denunciado a la policía por Danuta pero consigue liberarlos provocando un incendio en las cercanías del hotel, en el que muere abrasado el niño Pascal, hijo de Guiomar y Laura. Ésta le increpa y le recrimina con duras palabras, haciéndole responsable de la muerte de su hijo, y del papel tan pésimo que ha jugado en el grupo de 
compañeros del hotel : "Semea hil didak, Carlos" [...] "desgrazia bat izan haiz guztiontzat, taldeko okerrena [...]", (p. 346). Finalmente, Carlos se libera del acoso exterior e interior suicidándose en la charca, arrastrado por las aguas que llevan hacia una grieta que conduce a una sima sin salida.

Guiomar y Laura. Guiomar nació en Cuba pero, siendo niño, fue expulsado con su familia por la revolución castrista ; a pesar de ello, siempre le quedará el deseo de volver definitivamente a su país. Es amigo incondicional de Carlos y fue compañero de éste y Ugarte en un comando etarra donde era conocido con los apodos Foksi y Fangio. Se enamora de Laura, esposa de Ugarte, con la que había mantenido una relación sentimental en Francia tras la amnistía de 1977, antes de que aquellos contrajeran matrimonio. Fruto de ese amor pasajero es el niño Pascal. Ante la crisis matrimonial de Ugarte y Laura, y al comprobar que el niño es fruto de su antiguo amor, Laura y Guiomar deciden vivir juntos. Él es el jefe de compras del hotel y ella vive feliz a pesar de su dificil carácter : "[...] zaila duk eramaten", (p. 47). Se muestra dura con Ugarte a quien le trata de adúltero y de borracho. Lo más destacable de ella es la admiración mostrada a favor del leninismo así como las constantes conversaciones que mantiene con Danuta sobre el marxismo y la polaca Rosa Luxemburgo : "Danuta oso enteratuta zegok, eta hortxe ibiltzen dituk biak Rosa Luxemburgo gora eta Rosa Luxemburgo behera.", (p. 51).

Ugarte. Es un hombre de unos cuarenta años, pesa sesenta kilos y es fogoso("odol berokoa"). Laura lo compara con Noé por su afición al alcohol. Formó parte del comando de Carlos en el que era conocido por el apodo de Merkutxo. Es, además, un hombre desilusionado pero despierto e inteligente. Es una persona acabada y rota a consecuencia de su militancia pasada en el reino de "Don Miedo" y en "La Tierra sin amistad" ("Adiskiderik gabeko Lurrean). En el hotel, ocupa el puesto de administrador general. A pesar de mantener puntos de vista distintos con Carlos (especialmente en el tema del arriesgado compromiso de prestar cobijo a los dos miembros etarras en el hotel) no lo delatará a la policía y le será siempre fiel, colaborando en la liberación de Jon y Jone.

Danuta Wyka. En el lado opuesto a los tres ex-militantes etarras se halla esta intérpreta polaca destinada al servicio del equipo de fútbol de su país. Además de prestar esos servicios, juega un papel muy importante en la novela como delatora y confidente de la policia. Tiene unos sesenta años; estuvo casada con un cubano y al enviudar vive feliz con su familia. Se la describe como una figura pequeña de porcelana : "[...] portzelanazko figura ttiki bat ematen zuen [...]", (p. 43). Conoce perfectamente la ideología marxista y su llegada al hotel ha servido para que algunas otras personas como Laura, conozcan mejor la ideología de Rosa Luxemburgo. Dada la pobreza en la que viven en Polonia, pretende lograr los tres millones de recompensa que la policía española ofrece por la delación de los dos miembros etarras, Jon y Jone. Para ello, se sirve de la inocencia del niño Pascal (se la conoce como "la abuela" de Pascal) y de las conversaciones con Carlos (valiéndose de la ideología marxista) para denunciarle. Sus ideas revolucionarias chocan con la vida burguesa que ansía llevar, simbolizada en un par de pendientes de esmeralda, la marca de tabaco "Malboro", etc. : "Zer egingo zenuke zuk 
belarritako on batzuengatik? Benetako esmeraldaz egindakoengatik, esan nahi dut", (p. 226).

En la larga lista de personajes aparecen algunos otros considerados como secundarios pero que juegan un papel relevante en el desarrollo del suspense del relato ; entre ellos, incluiriamos a Mikel, Jon y Jone, y Pascal

Mikel. Es el vendedor de pescado que abastece al hotel de Carlos dos veces por semana (martes y viernes). Sirve, además, de enlace entre E.T.A. y Carlos, aprovechando los viajes que realiza entre el País Vasco y Barcelona. En su militancia etarra es conocido especialmente por el seudónimo de Neptuno. Es joven, hábil y astuto como lo demuestra en el primer encuentro mantenido con el Guardia Ezpainas en la carretera, y en el incendio provocado con Carlos para la liberación definitiva de Jon y Jone al final del relato.

Jone y Jon. Ambos pertenecen a un comando etarra muy violento. Tras el último atentado sangriento cometido en Bilbao, $y$ a falta de una infraestructura en el País Vasco, la organización decide sacarlos de allí y esconderlos durante una semana en el hotel de Carlos en Cataluña. Sus fotos aparecen en numerosos carteles y en la TVE, ofreciendo, a la vez, una recompensa de tres millones de pesetas por su delación. Aunque la prensa española los presenta afectivamente unidos como los protagonistas del film Bonnie \& Clyde (p. 28), ellos no son amantes; al contrario, terminan enfadándose dado el temperamento nervioso del jovencísimo Jon que apenas aparece en la novela y sufre depresiones de paranoia : ", Jon oso gaztea da eta berealditako neurarekin dago.", (p. 178). Jone, en cambio, se muestra como una militante más curtida. Su relación sentimental con Carlos, comenzada a raíz de su llegada al hotel, se interrumpe rápidamente por su puntos de vista distintos sobre la forma de actuar de E.T.A. : "Bien arteko distantzia nabarmen geratu zen bapatean $[\ldots] ",($ p. 40).

Pascal. Como hemos dicho anteriormente, es un niño de cinco años que, hasta casi el final de la novela, es considerado como hijo de Laura y Ugarte. Es el único niño del hotel y se distrae imaginándose ser Peter Pan o jugando a luchas de detectives. Sorprende fuera del escondite a Jon y Jone al anochecer, y ésta asustada saca su pistola. El niño relacionará esta imagen con la fotografia de Jone exhibida en los carteles puestos por la policia. La estrecha relación, con "su abuela Danuta" da pie para que ésta una lo narrado por el niño con la presencia del comando etarra en el hotel. La declaración de ella hecha a la policía dará pie a la búsqueda del comando aumentando así el suspense de la novela. Pascal morirá abrasado en el incendio provocado por Mikel y Carlos, concluyendo en éste una crisis psicológica que le conducirá al suicidio.

Entre los personajes secundarios, se halla también la gente empleada en el hotel entre la que destaca Doro como cocinero. Es un hombre de 52 años, delgado y huesudo ; antiguo jugador de cesta punta en La Florida y padre de dos hijos (Juan Manuel y Doro) que trabajan igualmente en el mismo hotel. Como ayudante de cocina tiene a Nuria, mujer joven y gruesa, que está en trámites de separación de su marido, y se relaciona sentimentalmente con Ugarte. El encuentro fortuito de Nuria 
con los agentes de la policía en los baños del hotel servirá para confirmar a Carlos en sus sospechas y aumentar el suspense de la novela. Como recepcionista y encargada de la centralita del hall del hotel (además de antigua azafata diplomada, y políglota) hallamos a Beatriz, "La nostra bellísima Beatriu", mujer casada de treinta años, que se resiste con orgullo ante el acoso de Carlos. Cierra esta lista, María Teresa, la amante y confidente de Carlos. Sólo ella y Guiomar conocen el escondite de la panadería donde Carlos oculta a Jon y Jone : "Gordelekua [...] Guiomarrek eta Maria Teresak bakarrik ezagutzen zuten barrutik [...]," (p. 141).

En el grupo policial compuesto de unos treinta agentes destacan Stefano, Ezpainas y Mario. Convencidos de que los dos etarras se hallan escondidos en el horno de la panadería ("labea interesatzen zitzaien gehiena", p. 261), visitan las dependencias del hotel con el pretexto de hacer un reportaje sobre el mismo. A medida que se cierra el cerco policial, la situación se hace insostenible pues los agentes acechan constantemente como un lobo lo hace con un erizo : "otsoak trikuarekin bezala", (p. 263). Stefano es un policía de elite, de ojos pequeños ; Carlos lo compara con una serpiente por su falsedad. Su compañero, apodado por Mikel como Ezpainas (Morros), es muy peligroso como lo pudo comprobar en un STOP de la carretera cercana al hotel, y un disparo efectuado en La Banyera. Además en un control de carretera Ezpainas para con malos modales a María Teresa y Carlos. Éste le trata de matón: "Baina, zer egiten duk! Hi zer haiz! Matoi bat?", (p. 298). Es un policía de seguridad que va siempre acompañado de su metralleta; Mikel le define como perro, en el peor de los sentidos. El joven Mario, policía de treinta años y miembro de la brigada antiterrorista, es el ayudante que colabora con Stefano.

Entre las personas que no toman una parte directa en la acción por haber fallecido pero que condicionan la vida de Carlos están su hermano Kropotki, Sabino y Rosa Luxemburgo.

Kropotki. Es el hermano mayor de Carlos y nació como éste en Obaba. Desde los catorce años era conocido en su pueblo por el apodo de Kropotki por la admiración que mostraba tras la lectura del libro Ogiaren konkista (La Conquista del Pan, 1888) del célebre anarquista ruso A.P. Kropotkin (1842-1921). Desde su juventud mostró también una fuerte afición al yoga y a las extrañas filosofias orientales. Según Carlos, no estaba loco sino que su comportamiento era un tanto peculiar y asocial por la influencia de dichas tendencias. Para blanquear el dinero robado en los atracos, Carlos le ingresa en un hospital psiquiátrico, a pesar de la resistencia de Kropotki : "Hemen utzi behar al nauk" (¿me vas a abandonar aquí?), (p. 175). Carlos siente pena, vergüenza y rabia por ello, y se sentirá culpable durante toda su vida pero no ve otro medio mejor para camuflar el capital obtenido mediante los atracos : "[...] amnistia ostean egindako atrakoetan lortutako kapitala oso ondo kamuflatuta baitzegoen", (p. 60). Acepta el plan propuesto por Ugarte que se autoproclama "rey de las finanzas". La argumentación de éste sobre la necesidad de ingresar a Kropotki y de declararle legalmente insolvente para que Carlos cobre una gran cantidad de millones, es muy clara. 


\section{"[...] hire anai sanatorio psikiatriko batean sartu} behar dugula [...] legalki eroa den batek ezin dik dirurik gastatu, ezin dik dirurik ukitu, ezin dik dokumenturik sinatu, esparru ekonomikoaren ezin dik ezer egin bere kabuz, eta beraz kasu honetan hi izango hintzateke, Carlos, bere berrogei edo berrogeita hamar milioien administratzailea $[\ldots]^{1,41}$

Kropotki pasó dos años en el hospital y falleció en él, agravando más el sentimiento de culpabilidad de Carlos. Durante esa época escribió varias cartas a su hermano ; en una de ellas le augura el fracaso de la lucha revolucionaria etarra : "Zuen iraultza handi hori ez duk behin ere aterako aurrera, eta are gutxiago Europako alde honetan", (p. 99).

Sabino. Este personaje (citado anteriormente como voz de la conciencia de Carlos) es otro de los fallecidos que cobra gran importancia en el desarrollo del relato. Fue amigo e instructor de aquél en la época de militancia de ambos en E.T.A. Murió en una emboscada en Bilbao y fue enterrado en un cementerio cercano a Biarritz quince años antes de los acontecimientos narrados en la novela.

La escritora y revolucionaria Rosa Luxemburgo, Roseta, es también un personaje influyente en la novela y en Carlos por el contenido ideológico marxista de sus numerosos escritos. Se la compara con la francesa Jeanne d'Arc, pero apostillando, a continuación, que aquélla fue muy superior a ésta en espíritu (p. 70). Los fragmentos de las cartas, y en general, sus escritos muestran la rica intertextualidad que presenta esta novela, v.g. : el comienzo de una carta enviada por ella en 1904 desde la cárcel de Zwickan, (p. 117); el amanecer visto por Roseta ochenta años antes, (p. 165) ; o el fragmento de otra carta escrita por ella desde la prisión de Breslau (p. 269-270).

Finalmente, existen también otros personajes que no tienen ninguna relevancia en la obra pero que ayudan a completar la verosimilitud de algunos de los acontecimientos históricos y deportivos narrados en ella : Boniek, Lato, Pelé, Maradona, Zico, Garrincha, Falcao, etc :, el Papa Woytyla, Walesa, Jaruzelski, F. Castro, la Virgen polaca de Chestozowa; la persona de Esther, amiga de Carlos y paisana de Obaba, quien le escribe varias cartas a la cárcel (p. 258) ; la mención de José Arregi (amigo de infancia del autor, militante etarra torturado y muerto en Madrid, (p. 265), o la del etnólogo y académico de la Academia Vasca, J.M. Satrustegi, (p. 129).

\section{Coordenadas espacio-temporales}

Toda la acción de la novela se desarrolla en torno a un hotel y sus alrededores. Se trata de un edificio situado en las cercanías del Monasterio de Montserrat, en el que se hospeda la selección polaca de fútbol. Es un edificio de sesenta habitaciones,

\footnotetext{
${ }^{41}$ Ibid. : 60 .
} 
en el que destacan el restaurante y, sobre todo, un gran salón con cincuenta butacas en el que tienen lugar las ruedas de prensa, y donde los huéspedes pueden ver la T.V. Junto a él, existe un bloque de apartamentos para los empleados y una panadería de $30 \mathrm{~m}^{2}$ donde trabaja Carlos ; en el sótano de ella se halla el horno y el escondite en el que permanecen los dos militantes de ETA. Es un lugar íntimo para el protagonista principal, su rincón de reflexión y también el nido para sus amores ocasionales. A unos cien metros de la panadería, hay una fuente que Guiomar ha bautizado con el nombre de La Fontana de Derby. En las proximidades del hotel se halla también una gran charca, La Banyera de Samsó, cuya superficie aparece en constante movimiento debido a una grieta por la que las aguas desaparecen en una sima. En las inmediaciones del hotel hay una cuesta montañosa (paso de huida del comando) y no lejos de ella, junto a la carretera, está la gasolinera, punto de partida de la liberación final de Jon y Jone. En este entorno cercado por la policía, y sofocante no sólo por el calor estival (con temperaturas de más de $30^{\circ}$ ) sino también por la tensión en que viven los personajes, se desarrolla la trama de este interesante relato.

Aunque la presencia del comando en el hotel dura casi dos semanas, el desarrollo de esta trama sólo se limita a los cinco últimos días, cuyo comienzo está concretado en el inicio de la novela : 28 de junio de 1982, (p. 9). Ese desarrollo es lineal y los acontecimientos van concatenados. El ritmo de los cuatro primeros días es normal, debido a los constantes flash-back que ralentizan la acción. En cambio, en el quinto y último día, ese ritmo cambia completamente ; todo se mueve con mucha celeridad y comienza la marcha atrás del relato, señalada por el autor con una numeración de 10 a 1 en las últimas páginas (306-349) de la obra. Algunas ideas y hechos que aparecieron en el comienzo de la novela hallan su explicación razonable y lógica al final de ella, gracias a la superposición de planos y a la concatenación de algunas frases. Así, por ejemplo, la novela arranca con un programa de televisión en la que Carlos escucha cómo hace 40.000 años los hombres primitivos se exponían al peligro por buscar en los mares helados conchas de color ("Nassa Reticulata"). Este hecho relacionado con una conversación mantenida con Danuta en La Banyera sobre unos pendientes de plástico de color verde que llevaba ésta (p. 759), y su deseo de poder comprar algún día unos pendientes de esmeraldas auténticas (aun corriendo el riesgo de ser delatora) serán asociados por Carlos al final de la novela (pp. 315-317) para despejar la incógnita del nombre del confidente de la policía. Esta asociación de ideas servirá de punto de inflexión en la súbita y repentina decisión tomada por Carlos de liberar cuanto antes al comando etarra.

\section{Estilo}

Uno de los aspectos más destacables de esta novela es, sin duda alguna, el esmerado cuidado mostrado por el autor en el aspecto formal de la misma : el desarrollo psicológico de los personajes ; las coordenadas de lugar y tiempo; la fuerza de los diálogos (v.g. : el mantenido entre Carlos y Jone, pp. 174-185); el monólogo interior; la belleza de las descripciones (pp. 81, 164-165, 167-169, etc.) ; las bonitas comparaciones (pp. 54, 55, etc.) ; el uso frecuente de la analepsis o 
flash-back; los símiles tan descriptivos como el de una libélula atrapada (como en una cárcel) en un vaso de cristal ; las cartas de Rosa Luxemburgo y de Kropotki ; los fragmentos de la canción del bardo vasco J.M. Iparragirre : "Hara non diran, mendi maiteak, hara non diran zelaiak", (p. 13) ; el himno de los gudaris : "Eusko gudariak", (p. 256) ; las frases francesas : "Tombe la neige, et ce soir tu ne viendras", (p. 129) o "C'est l'amour, mon ami", (p. 156), etc.

El vascuence de esta novela es también otro de sus aspectos mejor logrados. Se observa una mejoría notable con respecto a algunas de sus obras anteriores. No faltarán, sin embargo, lingüistas que critiquen este euskara funcional, pero de gran calado, capaz de expresar con fuerza y claridad temas relacionados con la política, el-marxismo, la religión, el deporte, el amor, el sexo, el cine, la prehistoria, la violencia, etc.

\section{Zeru horiek (1995)}

El título de la última novela publicada hasta ahora por el escritor B. Atxaga es Zeru horiek (Esos cielos) ; bien podía haberse titulado "Andrea bere bakardadean" (La mujer sola) por el tema de la soledad tan presente en ella. Zeru horiek sigue la línea del relato realista de Gizona bere bakardadean alejándose también de la fabulación mítica de las obras anteriores del autor de Asteasu. Entre los elementos comunes que se perciben entre ambas novelas pueden citarse : la presencia de las ciudades de Barcelona y Bilbao ; la pertenencia de los dos protagonistas (Carlos e Irene) a un grupo político radical (no se especifica el nombre del grupo en el caso de la mujer) ; el desamor que sienten estos dos personajes ; la reinserción tras la salida de la cárcel ; el tipo de vascuence tan semejante empleado por el autor en ambas novelas, etc. Por otra parte, en la lista de desemenjanzas existentes entre ambas obras, podemos anotar la diferente extensión pues la segunda es una novela corta de 141 páginas ; el escaso número de personajes que actúan en ésta ; la diferencia de sexo de los dos protagonistas; la gran importancia de los sueños que llegan a formar parte de la estructura de Zeru horiek, y, finalmente, el modo implícito de narrar que aflora en ella ; muy diferente de la manera detallista, concreta y explícita que el autor usó en Gizona bere bakardadean.

Zeru horiek gira en torno a una mujer de 37 años, que tras cuatro años de reclusión en la cárcel Modelo de Barcelona, vuelve a su ciudad natal, Bilbao : "Si me quieres escribir, ya sabes mi paradero en la celda número 12 de la cárcel Modelo"42. La novela narra principalmente los hechos, pensamientos y sueños de Irene durante las seis horas de autobús, que dura el viaje entre ambas capitales : "lokartu eta ametsetan hasi zen" (se durmió y comenzó a soñar), (p. 53). Se trata de una presa que, tras verse privada de libertad durante un período tan largo de tiempo, se halla ante un callejón sin salida. Para olvidar esa amarga experiencia se refugia en el espacio de cielo que divisa desde la ventana ; los films que va viendo en el televisor, y la relectura de los libros que porta en su maleta : la novela Le Rouge et le Noir (1831) de Stendhal en su versión casteliana ; el ensayo Quousque tandem...!

${ }^{42}$ B. Atxaga, Zeru horiek, Donostia, Erein, $1995: 39$. 
de J. Oteiza ; las poesías de la escritora estadounidense Emily Dickinson (18301886), etc.

En la corta lista de personajes destaca especialmente la protagonista cuyo nombre no aparece hasta la página 87 : "[...] Irene...zeren hori duzu izena, ez? Irene". Es una mujer silenciosa como consecuencia de los largos años de dura militancia que ha pasado cometiendo barbaridades (en opinión de un policía que viaja en el mismo autobús); su caso es parecido al de los veteranos de la guerra del Vietnam : "Urte asko dituzte disziplina gogor baten menpean eta basatikeriak egiten, eta gero ezin dira eguneroko bizitzara egokitu. Vietnamgo gerran ibilitako soldaduak bezala", (págs. 64-65). Se la ve sola, silenciosa y sin amor, como se puede comprobar por la cita de unos versos de su escritora favorita, E. Dickinson, que muestra la falsa esperanza en el amor.

"Last night I dreamt
that somebody loved me,
no hope, but no harm,
just another false alarm".

Su vida ha estado jalonada por hechos dramáticos que la han abocado a la soledad más absoluta. Convivió con un hombre (A. Larrea) que apareció en una playa, muerto por la policía "[...] Larrea hondartza batean hilda azalduko baitzen [...]. Poliziak jarritako enbuskada batean [...]". El último encuentro con él sirvió simplemente para confirmar la ruptura definitiva y despedirse para siempre : "just to say good bye". La falta de amor en la vida de Irene aparece sugerida por los dos conocidos versos del poeta romántico G. A. Bécquer (1836-1870) : "Volverán las oscuras golondrinas de tu balcón los nidos a colgar, pero aquellas que fueron testigo de nuestros amores, ésas no volverán", (págs. 114 -115). Ni siquiera su familia (padre y hermanos) la ha tratado con mucho cariño como se puede comprobar por las escasas visitas que ha recibido durante la larga estancia en la cárcel. La falta de calor humano se acentúa incluso con respecto a la organización armada en la que ha militado y que trata de abandonarla a pesar de que su nombre de reinsertada pueda aparecer como, "traidore eta chivata", (p. 107) en algún muro. En consecuencia, desea liberarse de su pasado, ahuyentando incluso los malos recuerdos de su vida anterior : "Alde hemendik! [...] halaxe uxatu beharko zituen bere pentsamendu gaiztoak."

Entre los personajes que forman el grupo cercano a Irene durante el viaje destacan una pareja de policías que intenta chantajearla recabando información sobre la muerte de A. Larrea ; otras dos monjas que sirven de contrapunto con respecto a los anteriores, y una señora corpulenta que trata de ayudarla. El desagradable incidente ocurrido en un hotel barcelonés en la primera noche después de su liberación (Irene hiere a un hombre con el que se acuesta y la trata de puta) servirá de excusa para que uno de los policías se muestre violento con elìa.

${ }^{43}$ Ibid. : 74. 
En cuanto al estilo y a las técnicas que emplea el autor en esta novela se pueden señalar los siguientes : el recurso de los sueños ; los distintos planos narrativos y de conciencia (su vida pasada como militante, como presa y como persona) ; la intertextualidad, y la simbología de la que se vale el autor. La intertextualidad es evidente por la inserción de numerosos fragmentos de poesía, prosa y de canciones : Michelangelo, E. Dickinson, J. Oteiza, C. Zavattini, J. Sarrionandia, G. Brassens, Violeta Parra, la canción popular vasca "Ixil ixilik dago...", etc. En esta larga lista de citas incluiríamos también unos versos de B. de Otero traducidos al euskara por B. Atxaga : "Gazte nintzenean, gogor mintzatu nintzen zure aurka, zu Bilbo magal nahasia izan baitziren niretzat, baina orain urruti nago eta hots egiten dizut, zure teilatuez gogoratzen naiz eta hots egiten ditzut..."44 (Yo, cuando era joven,/ te ataqué violentamente, $/[\ldots]$ ciudad donde nací, turbio de regazo/ de mi niñez [...]y pienso en tus tejados [...] y te llamo desoladamente [...]). Con respecto a los símbolos destacaríamos el del cielo multicolor que sirve de evasión de la realidad cotidiana a la protagonista. La ausencia de Dios en medio de la soledad sentida por Irene queda reflejada en un cuadro que su amiga Margarita le regaló como recuerdo de despedida. Es una imitación de las pinturas de la Capilla Sixtina en la que Michelangelo plasmó las imágenes de Dios y de Adán acercándo las manos pero sin llegar a estrecharlas.

"Nahiz eta besoa ahalik eta gehiena luzatu , Jainkoaren eta Adanen hatz indizeak (luzatuak, horiek ere) ez ziren ukitzen ; huskeria bategatik, tarte nimiño bategatik, baina ez ziren ukitzen."

\section{Literatura infantil y juvenil}

Al presentar la obra literaria de B. Atxaga mencionamos en la parte introductoria su variada y extensa producción resaltando la abundante literatura infantil en la que se pueden contar más de treinta obras. ${ }^{46}$ Dada la extensión de

\footnotetext{
44 Ibid. : 136. Los versos originales de este poeta bilbaino dedicados a su ciudad natal se pueden leer en el libro Pais. Antología 1955-1970. Madrid, Plaza \& Janés, S.A., 1971 : 129.

${ }^{45}$ B. Atxaga. Zeru horiek: 17.

${ }^{46}$ Amaren maitasuna bezalakorik ez duzu inon aurkituko (1990), Amazonas ibaian barrena (1990), Antonio Apreta (1998), Antonio Apretaren istorioa : "Siberia treneko ipui eta kantak" (1982), Astakiloak Arabian (1987), Astakiloak Finisterre aldean (1987), Astakiloak jo eta jo (1993), Astakiloen izkutuko taktika (1987), Asto bat hypodromoan (1984), Bambuloren istorio bambulotarrak. Krisia (1998), Bambuloren istorio bambulotarrak. Lehen urratsak (1998), Bambuloren istorio bambulotarrak. Ternuako penak (1999). Camilo Lizardi Erretore Jaunaren etxean aurkitutako gutunaren azalpena (1982), (Premio Ciudad de Irún), Chuch Aranberri dentista baten etxean (1982), Drink Dr. Pepper (1983), Emakume bakartia (1990), Flannery eta bere astakiloak (1987), Errugabeko txoriak ere erortzen dira sarean (1990), Gauero aterako nintzateke paseatzera (II) : Marieren azalpena ("Premio Ciudad de Donostia," 1984), Italiako zirku batean (1987), Jimmy Potxolo (1984), Kitarra baten bila gabiltza zoratzen (1987), Neska dun-dun bat (1987), Nikolasaren abenturak eta kalenturak (1980), Pelotari zaharraren ajeak (1990), Ramuntxo detektibea : Nikolasaren abentura gehio (1980), Ramuntxo detektibea (1993), Sara izeneko gizona(1996), Sara: Zumalakarregiren zelatari (1990), Su-koloreko ilea zuen emakumea (1990),
} 
nuestro artículo, dedicado especialmente al análisis de su novelística, no nos es posible prolongarlo mucho más, pero permítasenos, al menos, resumir brevemente dos relatos con el fin de adquirir un conocimiento más completo del arte literario de este célebre escritor. Se trata de los libros : Bi letter jaso nituen oso denbora gutxian (Recibí dos cartas en muy poco tiempo) y Sugeak txoriari begiratzen dionean (Cuando la serpiente mira al pájaro).

\section{Bi letter jaso nituen oso denbora gutxian}

En la larga lista de libros de B. Atxaga este relato (equiparable a un cuento largo) destaca como uno de los más atrayentes por el humor, la viveza y frescura de su lenguaje híbrido (euskara e inglés), y los recuerdos etnológicos y folclóricos que ofrece sobre el pasado de País Vasco. El protagonista es un hombre de casi ochenta años que vive en Boise, después de haber pasado sesenta años como pastor en las montañas de Idaho. En el corto intervalo de quince días recibe, remitidas de Obaba, dos cartas escritas por los familiares de dos amigos suyos de juventud, en las que se le comunica el fallecimiento de Beltza (el Negro) y de Iharra (el Flaco). El anciano pastor, conocido entre los vascos de Boise como Old Martin, relee estas cartas y llega a la conclusión de que ambos han muerto sin haberse reconciliado, a causa de un desagradable incidente que propició (convirtiendo en realidad) el sueño del joven Martín Agirre, de emigrar a las Américas.

Esta narración cuenta una doble historia bien concatenada : la del pasado remoto del joven Martín Agirre en Obaba y la del pasado más próximo de Old Martin en Idaho. En ambas historias se multiplican los recuerdos que se superponen constantemente mediante las múltiples interrupciones del hilo narrativo, que no impiden, sin embargo, la fácil lectura del relato. Con el símil del descarrilamiento de un tren, Old Martín describe sus, interrupciones como narrador : "Baina deskarrilatu egin naiz ostera", (p. 20). Él es el personaje principal y, a la vez, el narrador que cuenta generalmente en primera persona, pero que se vale también de la tercera persona en raras ocasiones: "Old Martinek, hasieran ere esan dut, Old Martinek pentsatzeko ohitura berezia eduki du beti [...]", (p. 84). En la primera parte de la historia, vemos al joven Martín que trabaja como leñador en los montes de Obaba en compañia de sus dos amigos : Beltza e Iharra. El primero de ellos aparece descrito como fuerte pero arrogante, pendenciero, mujeriego y muy tramposo ; el segundo en cambio, es fisicamente menos fuerte pero está presentado como leal y buen trabajador: "Iharra beste terraje bateko mutila zen. Triste xamarra, baina leiala, langile ona. " (p. 29). Éste vence a Beltza en una prueba de levantamiento de una piedra cilíndrica, en la cual se ha apostado mucho dinero y ha sido presenciada por tres mil espectadores. El desafio ha estado amañado por el propietario de la piedra (un señor mayor de fuera de Obaba) con la connivencia del entrenador de Beltza. El joven Martín, enterado secretamente de la trampa urdida contra éste, apuesta una suma grande de dinero a favor de Tharra quien se proclama

Transatlantiko butean (1987). Txitoen istorioa (1984), Xolak badu lehoien berri (1995), Xola eta basurdeak (1996), Xola ehizan (2000). 
campeón. Con ese dinero ganado podrá 'pagar el billete del embarque que, tres meses más tarde, le llevará a las Américas.

Tras más de medio siglo de pastoreo en las montañas de Idaho desciende a su capital, Boise, donde vive con su esposa, María, que morirá dos años más tarde en un accidente de coche. Old Martin comienza a narrar la segunda parte de la historia de su vida en la que no faltarán ni alegrías ni penas. Las frecuentes comparaciones entre la penuria, pobreza y subdesarrollado económico que conoció en Obaba contrastan con el progreso y bienestar material de los que goza en Boise.

"Ene herrian bizi izan nintzen artean, zer eduki nuen ba? Ezerrez, hitz gutxitan esateko. Patata egosia eta baba jateko. Jazteko zarpa batzuk, hemengo mendicant utzienak ere eramango ez lituzkeen modukoak. Hanketan berriz, apreta zaharrak [...]. Orain sikera [...] badut etxe bat bere garden eta guzti [...] Honelaxe bizi naiz orain, gardenia zaintzen eta paseoak ematen, etorkizunaren batere beldurrik gabe".

(Pues, ¿qué poseía yo mientras viví en mi pueblo? Para decirlo en pocas palabras, nada. De comer, patatas cocidas y habas. De vestir, unos harapos que no se pondría ni el mendigo más pobre de aquí. Y en los pies, unas alpargatas viejas. [...]A hora, al menos tengo una casa con un jardín. Vivo cuidando el jardín y dando paseos sin temor al futuro.)

Pero no todo es felicidad en la dulce tierra prometida de América. Al enviudar, Old Martin vive en casa de un hijo casado con una mujer de origen irlandés, Kathleen, y de un nieto de ocho años, Jimmy. Las discusiones con la nuera son frecuentes y los problemas de soledad e incomunicación se van acentuando a medida que pasan los años y se llega a la vejez : "[... nazka ematen du zaharra izateak, emakume kapritxoso baten mende gelditzen zara", (p. 17). El bajo nivel de su inglés impide al anciano Martín la correcta comunicación con Kathleen y, sobre todo, con Jimmy a quien le gustaría contar su pasado.

El estilo de este libro resalta por las expresiones populares, la viveza de su lenguaje, las frases cortas y expresivas, y las comparaciones, como la que hallamos en la pág. 21 al relacionar la flaqueza de la memoria de Old Martin con la llegada lenta de la luz eléctrica tras un corte debido a una tormenta : "Memory ahul hura funtzionatzen hasi zitzaidan ostera, joandako argindarra berriro - ekaitza pasatakoan edo - etortzen denean bezalaxe [...]". El elevado número de vocablos ingleses es otro aspecto positivo de este libro cuyo lenguaje híbrido se asemeja al euskara hablado por muchos vascos actuales en el Oeste de los Estados Unidos. Sin ánimo de lograr una lista completa ofrecemos algunas de las palabras inglesas más

${ }^{47}$ Bernardo Atxaga. Bi letter jaso nituen oso denbora gutxian, (7.ed.), Donostia, Erein, $1990: 9$. 
frecuentes que usa Old Martin en su conversación diaria : garden, very nice, school, English, beautiful, mister, my country, post-office, cartoon, old, Christmas Day, father, pudding, drugstore, ice box, wonderful, city, fire-works, my lord, game, your fault, hair dressing, shop, pastry, mouse, cheese, cake, grandfather, please, etc.

\section{Sugeak txoriari begiratzen dionean (1984)}

El año 1984 fue muy productivo en el haber literario de B. Atxaga pues, además de varios cuentos publicó tres libros importantes : Bi letter jaso nituen oso denbora gutxian, Bi anai y Sugeak txoriari begiratzen dionean. ${ }^{48}$ Estas tres obras guardan varios elementos en común pues describen el mundo de la infancia y de la vejez; más aún, al final de los dos últimos libros hallamos un paralelismo evidente en la aparición de unas ocas que forman unas letras en el firmamento, sugiriendo de este modo la muerte de los protagonistas.

Una vez más, el autor sitúa este cuento en Obaba, lugar mítico e imaginario donde se encuadran muchas de sus obras. En esa ubicación habitual y familiar se desarrolla esta obra cuyos temas se relacionan directamente con el amor, la naturaleza, la vejez y la adolescencia (representadas en el abuelo Martín y el nieto Sebastián Bera), la locura y el anuncio solapado de la muerte, la soledad y la incomunicación. Durante el desarrollo de la obra se van mezclando diversos elementos de ficción con hechos reales de la vida cotidiana : la hipnosis que sufre el pájaro ante la mirada ofuscadora de la serpiente ; la capacidad mágica del abuelo para comunicarse con los animales (su burro Fangio, el pájaro, la serpiente a la que reprende, los jabalíes del bosque, las truchas, los perros y los gatos de Obaba). Pero ni la gente del pueblo, ni su propia familia dan crédito a ello y le tienen por loco al anciano Martín que amenaza repetidas veces con marcharse a Terranova. Ante la pregunta del nieto sobre la decisión de partir a un país frío y helado, el abuelo responderá con la realidad de otro tipo de frío que hiela su existencia en Obaba.

\section{- " Baina aitona! Zergatik joan nahi duzu Terranovara? Han jela eta hotza besterik ez dago! \\ Eta hemen? Hemen ez al dago jela eta hotzik?"49}

Los personajes principales del cuento son el abuelo Martín y su nieto, Sebastián Bera, adolescente de trece años, que se enamora de Mariatxo durante las vacaciones de verano que pasa en Obaba, en casa de sus tíos. A medida que "el primo amore" entre los dos jóvenes avanza en la segunda parte de la obra, la presencia de Mariatxo irá creciendo mientras que el protagonismo del abuelo (tan evidente en la primera parte) irá decreciendo, hasta llegar a la desaparición final marcada por el vuelo de los gansos : "AIO MARTIN", (p. 50).

\footnotetext{
${ }^{48}$ Los títulos de estos cuentos son : Asto bat hypodromoan, Jimmy Potxolo, Txitoen istorioa, Gavero aterako nintzateke paseatzera (II) : Marieren Azalpena.

${ }^{49}$ Bernardo Atxaga. Sugeak txoriari begiratzen dioenean, (6. Ed.), Donostia, Erein, 1991: 37.
} 
Las disquisiciones sobre el amor juvenil representadas en las relaciones de Martín (nuevo "Robinson Crusoe") y Mariatxo ; las bonitas comparaciones (v.g. : págs : $18,34,45$ ), la belleza, claridad y sencillez del lenguaje de una obra destinada al mundo infantil, son algunos de los elementos que atraen al lector y que, sin duda alguna, tuvieron en cuenta los miembros del jurado al galardonar esta obra en 1983 cun el premio "Xabier Lizardi Saria" del Ayuntamiento de Zarauz.

Concluyamos este trabajo afirmando que B. Atxaga ha demostrado que el euskara es una lengua tan idónea como cualquier otra para lograr una creación literaria de gran calado. Asimismo ha probado que la literatura vasca está alcanzando un nivel tan alto como el de otras literaturas por el poder de sugerencia, la fantasía, el humor, la ternura, los diferentes tonos de voz, etc. Recientemente ha sido galardonado con el Premio Eusko Ikaskuntza - Caja Laboral de humanidades, Cultura, Artes y Ciencias Sociales. El juradó destacó que B. Atxaga "es un escritor que no sólo tiene éxito mediático y ha creado una obra traducida a muchos idiomas, sino que en lo más profundo de su creación se encuentra una voz intensa y diferenciada. Ha creado un estilo a partir de una sociedad, la vasca, y un idioma, el euskera, demostrando que se pueden alcanzar valores universales desde esta sociedad."

EI) Elario Vasco, 7-VI-2002 